\title{
Size-dependent compressive strength properties of hard rocks and rock- like cementitious brittle materials
}

Mohammad Darbor ${ }^{\mathrm{a}}$, Lohrasb Faramarzi ${ }^{\mathrm{a} *}$ and Mostafa Sharifzadeh ${ }^{\mathrm{b}}$

${ }^{a}$ Department of Mining Engineering, Isfahan University of Technology, Isfahan 8415683111, Iran;

${ }^{b}$ Department of Mining Engineering, Western Australian School of Mines (WASM), Curtin University, Bentley, Australia

Corresponding author address: Department of Mining Engineering, Isfahan University of Technology, Isfahan 84156-83111, Iran. Tel: +98 913 3585137, Fax: +98 313 3912776, E-mail address: lfaramarzi@cc.iut.ac.ir

\section{Acknowledgements}

The authors would like to thank the staff of Western Australian School of Mines (WASM), Curtin University, Australia for their kind help during the research period. 


\title{
Size-dependent compressive strength properties of hard rocks and rock-like cementitious brittle materials
}

\begin{abstract}
Rock engineering projects have always been constructed on different (from micro to macro) scales. This makes understanding rock behavior at different scales essential. In previous statistical studies on igneous hard rocks, the correlation of uniaxial compressive strength values in different diameters with estimations of specimen size-effect models was weak. In view of this knowledge gap, the present research proposed a model of appropriate size-effect in igneous hard rocks. This research also aimed at discussing the effect of specimen size and grain size on the uniaxial compressive strength of concrete specimens. To achieve these aims, studies were conducted in parallel on the previous and new experimental data. Non-linear regression analysis on igneous hard rocks indicated that there is a better agreement between the outputs of the multifractal scaling model and the specimen size-effect model using the fracture energy theory and the results of previous laboratory tests. In addition, in the experimental study, the grain size effect on the predictions of specimen size-effect models was exhibited. The results of this research can be used for designing engineering projects at different scales.
\end{abstract}

Keywords: Specimen size-effect; grain size effect; uniaxial compressive strength; statistical analysis; fracture energy

\section{Introduction}

In rock engineering, the effect of scale on the strength and deformation properties of a rock mass is one of the most important issues. Dependence of the compressive strength on the specimen size plays a fundamental role in designing rock structures. One example relates to the room and pillar mining method, which relies on the strength of pillars to support underground openings. However, pillar sizes and thus their strengths can vary significantly (Masoumi, Douglas \& Russell, 2016). Laboratory strength measurements made on small samples are to be corrected so that they can be suitably applied to the design of larger rock structures. Previous studies have shown that uniaxial compressive strength (UCS) of intact rock decreases as specimen size increases. However, its 
variations depend on a number of parameters such as the type of rock, mineralogical composition, and porosity (Poulsen \& Adhikary, 2013; Yoshinaka, Osada, Park, Sasaki $\&$ Sasaki, 2008). It eventually becomes difficult to determine the strength characteristics of actual-scaled samples from equipment cost and loading capacity perspectives. Therefore, it is worth estimating the strength characteristics of actual-scale intact rock using laboratory tests and specimen size-effect models (Bazant, 1997; Bazant \& ASCE, 1984; Carpinteri, Chiaia \& Ferro, 1995; Hoek \& Brown, 1980; Masoumi, Saydam \& Hagan, 2015; Weibull, 1951).

In rock mechanics, many experimental and analytical methods have been utilized to evaluate the specimen size-effect on the mechanical behavior of intact rock. Experimental methods include uniaxial compressive strength (Baecher \& Einstein, 1981; Darlington \& Ranjith, 2011; Masoumi et al., 2015; Mogi, 1962; Pells, 2004; Thuro, Plinninger, Zah \& Schutz, 2001a), triaxial compressive strength (Aubertin, Li \& Simon, 2000; Hunt, 1973; Masoumi, Roshan \& Hagan, 2016; Medhurst \& Brown, 1998; Singh \& Huck, 1972), point load (Bieniawski, 1975; Forbes, Masoumi, Saydam \& Hagan, 2015; Greminger,1982; Hawkins, 1998; Thuro, Plinninger, Zah \& Schutz, 2001b) and indirect tensile testing (Andreev, 1991a, 1991b; Butenuth, 1997; Canakci \& Pala, 2007; Carpinteri et al., 1995; Elices \& Rocco,1999; Thuro et al., 2001a). Analytical methods can be divided into three categories: statistical theories, empirical and semi-empirical models, and theories based on fracture mechanics. The following studies used statistical theories: Weibull (1939), Bieniawski (1968), Pretorius and Se (1972), Bazant (Bazant \& ASCE, 1984; Bazant \& Chen, 1997; Bazant \& Planas, 1998; Bazant \& Oh, 1983), Darlington and Ranjith (2011), Manouchehrian, Sharifzadeh and Hamidzadeh Moghadam (2012) and Masoumi et al. (2015, 2016). The empirical and semi-empirical size-effect models were utilized in the studies by Mogi (1962), Hoek and Brown (1980), Yoshinaka et al. 
(2008) and Darlington and Ranjith (2011). Theories based on fracture mechanics were used in studies by Griffith (1924), Adey and Pusch (1999), Bazant (1993), Carpinteri (Carpinteri, 1994; Carpinteri et al., 1995; Carpinteri \& Mainardi, 1997) and Masoumi et al. (2016). In the areas of rock mechanics and solid mechanics, the most notable analytical models proposed to predict specimen size-effect on uniaxial compressive strength include the Weibull statistical theory (Weibull, 1951), the Hoek and Brown empirical model (Hoek \& Brown, 1980), the multi-fractal scaling model (Carpinteri et al., 1995), the specimen size-effect model using the fracture energy theory (Bazant \& ASCE, 1984), the fractal fracture size-effect model (Bazant, 1997) and the unified size-effect model for intact rock (Masoumi et al., 2015).

To specify the application scope of specimen size-effect models in rock and concrete specimens, few significant studies have so far been carried out. By structural classification of various rocks and using five different relational models, Darlington and Ranjith (2011) determined the determination coefficient values of each model and concluded that there were large variations in the results even in one type of classification because of the specimen size-effect. In each of the defined models, the relationship between specimen size and specimen strength in igneous hard rocks is weaker than that in sedimentary rocks. The study by Masoumi et al. (2015) indicated that the unified sizeeffect model exhibited good results in some sedimentary rocks. However, one of the defects of this model is that it is not always possible to perform several laboratory tests on different diameters to achieve appropriate dispersion around the given diameter with maximum strength.

In view of these knowledge gaps, this research proposes a model of appropriate size-effect in igneous hard rocks and concrete specimens. The present study also aimed to discuss the effect of specimen size and grain size on the uniaxial compressive strength 
of rock and concrete specimens using statistical and experimental methods. To this end, studies were conducted in parallel on the previous and new experimental tests. Figure 1 shows the principle steps of the present research for assessing specimen size-effect and grain size-effect on uniaxial compressive strength.

Figure 1. Procedure for assessing specimen size-effect and grain size-effect on uniaxial compressive strength applied in this research.

\section{Background of specimen size-effect theories}

The theories of specimen size-effect on uniaxial compressive strength can be divided into five categories: empirical, statistical, multi-fractal, fracture energy and fractal fracture theories. In the empirical, statistical, multi-fractal and fracture energy models, uniaxial compressive strength indicates a descending trend with increasing the specimen diameter.

\subsection{The empirical study of specimen size effect (Hoek and Brown model)}

Figure 2 shows specimen size effect on the uniaxial compressive strength of an intact rock (Hoek, 2000). Equation (1) indicates specimen size effect on uniaxial compressive strength. In this Equation, $\sigma_{\mathrm{cd}}$ is the uniaxial compressive strength of cylindrical specimens with an arbitrary diameter $(\mathrm{d}: 10-200 \mathrm{~mm})$, and $\sigma_{\mathrm{c} 50}$ is the uniaxial compressive strength of a cylindrical specimen $50 \mathrm{~mm}$ in radius.

$$
\sigma_{\mathrm{cd}}=\sigma_{\mathrm{c} 50}(50 / \mathrm{d})^{0.18}
$$

Equation (1) shows a descending trend of compressive strength with increasing the diameter (Hoek \& Brown, 1980). As shown in Figure 2, this study was undertaken in hard rocks such as limestone, granite and basalt. Therefore, investing scale effect in soft rocks is also required (Yoshinaka et al., 2008). 
Figure 2. The effect of specimen size on the uniaxial compressive strength of intact rocks (Hoek, 2000).

\subsection{Specimen size effect based on the Weibull statistical theory}

Weibull proposed a statistical distribution for strength as a function of specimen size. The distribution can predict specimen size effect through the data scatter of experimental results (Equation 2):

$$
\mathrm{P}_{\mathrm{f}}\left(\sigma_{\mathrm{N}}\right)=1-\exp \left[-\int_{\mathrm{V}} \mathrm{C}\left(\sigma(\mathrm{x}), \sigma_{\mathrm{N}}\right) \mathrm{dV}(\mathrm{x})\right]
$$

where $\sigma$ is the stress tensor field induced by the load corresponding to the nominal stress $\sigma_{\mathrm{N}}, \mathrm{x}$ is coordinate vector, $\mathrm{V}$ is the volume of a specimen, and $\mathrm{C}(\sigma)$ is the function giving the spatial concentration of the failure probability of the material (Bazant et al., 2004; Ovalle, Frossard, Dano, Hu, Maiolino \& Hicher, 2014).

Weibull assumed that the probability of the failure of a solid body made of smaller particles is a function of its volume (Equation 3):

$$
\mathrm{m} \log \left(\sigma_{\mathrm{c}} / \sigma_{\mathrm{c} 0}\right)=\log \left(\frac{\mathrm{V}_{0}}{\mathrm{~V}}\right)
$$

where $\mathrm{m}$ is a material constant called the coefficient of uniformity, $\sigma_{\mathrm{c}}$ is the uniaxial compressive strength of the specimen, $\sigma_{\mathrm{c} 0}$ is the uniaxial compressive strength of a standard size specimen, and $V_{0}$ is the volume of a standard size specimen (Yoshinaka et al., 2008; Zhang, Zhu, Zhang \& Ding, 2011).

The Weibull distribution is acceptable for brittle structures as well as largeenough quasi-brittle structures, in which the failure of one small elementary volume of the material causes the whole structure to fail. 


\subsection{The multifractal scaling model (MFSL)}

Based on the concept of multifractality, Carpinteri et al. (1999) proposed an analytical model for measuring specimen size-effect. The model, known as the multifractal scaling model (MFSL), is illustrated in Equation (4) and Figure 3:

$$
\sigma_{\mathrm{N}}=\mathrm{f}_{\mathrm{c}}\left(1+\mathrm{l}_{\mathrm{ch}} / \mathrm{D}\right)^{1 / 2}
$$

where $\sigma_{\mathrm{N}}$ is the nominal compressive strength; $\mathrm{D}$ is the characteristic sample size; and the constants $f_{c}$ and $l_{c h}$ represent the nominal compressive strength of an infinitely large specimen and an internal material length, respectively. The constants can be determined in each case by means of a non-linear least-squares fitting algorithm from the experimental results related to geometrically similar specimens with various sizes. Carpinteri, Chiaia and Ferro (1995) conducted an extensive study on the available empirical data, showing that the multifractal scaling model estimates the strength of unnotched structures well.

Figure 3. Scale effects according to the multifractal scaling model (Carpinteri et al., 1999).

\subsection{The specimen size-effect model using the fracture energy theory (SEL)}

Examining the energy balance in crack propagation, Bazant and ASCE (1984), Bazant (2004) and Bazant, and Vorechovsky and Novak (2007) derived two specimen size-effect model for geometrically similar concrete structures with different sizes. Type II size effect (SEL-II) for failures with large cracks or notches is shown by Equation (5):

$$
\sigma_{\mathrm{N}}=\mathrm{P} / \mathrm{bD}=\mathrm{Bf}_{\mathrm{t}}^{/}\left(1+\mathrm{D} / \mathrm{D}_{0}\right)^{-1 / 2}
$$


where $\sigma_{\mathrm{N}}$ is the nominal strength; $\mathrm{P}$ is the maximum applied load or the load parameter; $b$ and $D$ are the specimen thickness and diameter, respectively; $f_{t}^{/}$is a strength parameter; $\mathrm{B}$ and $\mathrm{D}_{0}$ are parameters which depend on the structural geometry that can be determined by fitting experimental data.

Many quasi-brittle structures, however, fail at crack initiation from a smooth surface when the fracture process zone or the boundary layer of cracking develops fully. In that case, size effect is type I (Bazant, ASCE, Vorechovsky \& Novak, 2007; Bazant \& $\mathrm{Yu}, 2009)$ and is shown by Equations (6) and (7):

$$
\begin{gathered}
\sigma_{\mathrm{N}}=\mathrm{f}_{\mathrm{r}}{ }^{\infty}\left[\left(\mathrm{l}_{\mathrm{s}} /\left(\mathrm{D}+\mathrm{l}_{\mathrm{s}}\right)\right)^{\mathrm{rn} / \mathrm{m}}+\left(\mathrm{rD}_{\mathrm{b}} /\left(\mathrm{D}+\mathrm{l}_{\mathrm{p}}\right)\right)\right]^{1 / \mathrm{r}} \\
\text { If } \mathrm{m} \rightarrow \infty, \sigma_{\mathrm{N}}=\mathrm{f}_{\mathrm{r}}^{\infty}\left[1+\left(\mathrm{rD}_{\mathrm{b}} /\left(\mathrm{D}+\mathrm{l}_{\mathrm{p}}\right)\right)\right]^{1 / \mathrm{r}}
\end{gathered}
$$

where $\mathrm{f}_{\mathrm{r}}{ }^{\infty}, \mathrm{D}_{\mathrm{b}}, \mathrm{n}, \mathrm{m}$ and $\mathrm{r}$ are positive constants for geometrically similar specimens $(\mathrm{rn} / \mathrm{m}<1) ; \mathrm{f}_{\mathrm{r}}{ }^{\infty}$ is nominal strength for a very large structure; $\mathrm{D}$ is the characteristic size of the structure; $D_{b}$ is the effective thickness of the boundary layer; $l_{s}$ is second (statistical) characteristic length; and $\mathrm{l}_{\mathrm{p}}$ is material characteristic length (Bazant, 2004; Bazant \& Yu, 2009). According to experimental data, the optimum r-value lies generally between $1 / 2$ and 1 , depending on the coefficient of variation of random material strength. For small D, this formula converges to Equation (7), and, for large D, it converges to the Weibull size-effect $\sigma_{\mathrm{N}} \propto \mathrm{d}^{-\mathrm{n} / \mathrm{m}}$ (Bazant \& Pang, 2007; Bazant \& Yu, 2009). The Bazant model is suitable for quasi-brittle and brittle materials such as rock and concrete (Masoumi et al., 2015).

\subsection{The fractal fracture size-effect model (FFSEL)}

Bazant used the fractal concept in the failure energy and proposed the fractal fracture size-effect model (FFSEL) (Equation 8): 


$$
\sigma_{\mathrm{N}}=\left(\sigma_{0} \mathrm{D}^{\left(\mathrm{d}_{\mathrm{f}}-1\right) / 2}\right)\left(1+\left(\mathrm{D} / \mathrm{D}_{0}\right)\right)^{-1 / 2}
$$

where $\sigma_{0}$ is the strength of a sample with a negligible size, which may be expressed in terms of an intrinsic strength; $\mathrm{d}_{\mathrm{f}}$ is the fractal dimension; and other constants are the same as those defined for the SEL-II model (Equation 5). Fractal properties are obtained using the fractal dimension $\left(d_{\mathrm{f}}\right)$ :

- $\mathrm{d}_{\mathrm{f}}=1$ for nonfractal characteristics

- $\mathrm{d}_{\mathrm{f}} \neq 1$ for fractal characteristics

The structure of the SEL-II and FFSEL models are very similar. For determining $\sigma_{0}$ and $d_{f}$ in the FFSEL, it is required that $D_{0}$ be initially determined from the SEL-II and then $\sigma_{0}$ and $d_{\mathrm{f}}$ be calculated for the FFSEL using non-linear regression analysis. For sizes that indicate nonfractal characteristics, $\mathrm{d}_{\mathrm{f}}=1$, and the FFSEL is the same as SEL-II, where $\mathrm{Bf}_{\mathrm{t}}^{/}=\sigma_{0}$ (Masoumi et al., 2015).

\section{The study of specimen size-effect on uniaxial compressive strength}

To study specimen size-effect on uniaxial compressive strength, two studies were conducted in parallel. First, the results of previous studies performed by different researchers on igneous hard rocks and artificial samples were collected. As in previous studies conducted by other researchers on different rocks (Table 1), the relationship between specimen size and specimen strength in igneous hard rocks was weak, this surveying focused on igneous hard rocks. In these rocks, four types of granite, a type of andesite and a type of tuff, and, in artificial samples, a type of concrete with three different water/cement ratios (w/c) and a type of plaster were studied. There were 32 igneous hard rock samples with the diameters of 13 to $294.8 \mathrm{~mm}, 20$ artificial concrete samples with the diameters of 50.8 to $914.4 \mathrm{~mm}$, and 6 plaster specimens with the diameters of 25.3 to 
$152.3 \mathrm{~mm}$. In the experimental study, 84 concrete samples with four diameters and three grain sizes were prepared, and the influence of specimen size and grain size on compressive strength was studied.

Table 1. Major studies conducted on the scale effect on the compressive strength of rock and concrete specimens.

\subsection{Specimen size effect on the compressive strength of igneous hard rocks}

Thuro et al. (2001a) investigated the strength of four granite specimens with the diameters of 51 to $112 \mathrm{~mm}$. Experimental data and the results of statistical analysis by three models of MFSL, SEL-I and Hoek-Brown are shown in Figure 4. The constants of MFSL and SEL-I models were determined in each case from the experimental results by means of a non-linear least-squares fitting algorithm and the Levenberg-Marquardt method. As shown in Figure 4, the SEL-I and MFSL models indicated highest determination coefficient values $\left(R^{2}=0.23\right)$.

Figure 4. The prediction of uniaxial compressive strength in different diameters for granite specimens (Thuro et al., 2001a) using specimen size effect models of MFSL, SELI and H-B.

Figure 5 presents the results of the research conducted by Hoskins and Horino (1969) for three granite specimens with diameters of 25 to $76 \mathrm{~mm}$. As can be seen in this figure, determination coefficient values for each of the three models are approximately equal, but the $\mathrm{H}-\mathrm{B}$ model estimated the strength in the diameter of $25 \mathrm{~mm}$ much more than the experimental values.

Figure 5. The prediction of uniaxial compressive strength in different diameters for Salida granite (Hoskins \& Horino, 1969) specimens using the specimen size effect models of MFSL, SEL-I and H-B. 
Jackson and Lau (1990) studied the results of laboratory tests on granite specimens with the diameters of 32.8 to $294.8 \mathrm{~mm}$ (Figure 6). Their work displayed a decrease in strength with increasing specimen size. However, the strength was not as significant as what is predicted by Equation (1). Again, in this case, the SEL-I and MFSL models presented the highest determination coefficient values $\left(R^{2}=0.39\right.$ and $R^{2}=$ 0.37, respectively).

Figure 6. The prediction of uniaxial compressive strength in different diameters for Lac du Bonnet granite (Jackson \& Lau, 1990) specimens using the specimen size effect models of MFSL, SEL-I and H-B.

Nishimatsu et al. (1969) studied samples including Saajome andesite with the diameters of 24 to $70 \mathrm{~mm}$, Ogino tuff with the diameters of 17 to $70 \mathrm{~mm}$ and Inada granite with the diameters of 13 to $70 \mathrm{~mm}$ to find the relationship between the diameter and the strength of specimens. The uniaxial compressive strength tests conducted on Saajome andesite indicated strong size effect in MFSL, SEL-1 and H-B models (Figure 7). The results of studies on other rock types presented extended distribution (Figures 8 and 9). The MFSL and SEL-1 models showed highest determination coefficient values in these samples.

Figure 7. The prediction of uniaxial compressive strength in different diameters for Saajome andesite (Nishimatsu et al., 1969) specimens using specimen size effect models of MFSL, SEL-I and H-B.

Figure 8. The prediction of uniaxial compressive strength in different diameters for Ogino tuff (Nishimatsu et al., 1969) specimens using specimen size effect models of MFSL, SEL-I and H-B.

Figure 9. The prediction of uniaxial compressive strength in different diameters for Inada granite (Nishimatsu et al., 1969) specimens using specimen size effect models of MFSL, SEL-I and H-B. 
The determination coefficient values of MFSL, SEL-I and Hoek-Brown models for different types of igneous hard rocks are illustrated in Table 2. As can be seen in this table, among different theories on the types of igneous hard rocks, MFSL and SEL-1 models indicated a better correlation with the results of laboratory tests. In addition, the determination coefficient values of MFSL and SEL-I models were approximately equal for the studied igneous hard rocks. But this conclusion in other structural classifications is not accurate. For example, Figures 10 and 11 show two types of sedimentary rocks that were studies by Hoskins and Horino (1969). The regression analysis conducted on these rocks showed that the predictions and determination coefficient values of MFSL and SEL-I models had significant differences.

Table 2. The determination coefficient values $\left(\mathrm{R}^{2}\right)$ and parameters of MFSL, SEL-I and Hoek-Brown models for different types of hard igneous rocks obtained by regression analysis.

Figure 10. The prediction of uniaxial compressive strength in different diameters for Longmont sandstone (Hoskins \& Horino, 1969) specimens using specimen size effect models of MFSL, SEL-I and H-B. The MFSL and SEL-I lines were only fitted to the data $>50 \mathrm{~mm}$.

Figure 11. The prediction of uniaxial compressive strength in different diameters for Kansas limestone (Hoskins \& Horino, 1969) specimens using specimen size effect models of MFSL, SEL-I and H-B. The MFSL and SEL-I lines were only fitted to the data $>50 \mathrm{~mm}$.

\subsection{Specimen size effect on the compressive strength of artificial specimens}

Beginning in the 1980s, specimen size effect was investigated in quasi-brittle materials such as concrete structures (Yoshinaka et al., 2008). Today, among the quasi-brittle and brittle materials, the most comprehensive studies on size effect have been conducted on concrete specimens. Bazant and Van Mier were the first researchers in this respect. 
Bazant improved the knowledge of size effect theoretically, while Van Mier focused on experimental studies (Carpinteri et al., 1995).

Blanks and McNamara (1935) studied the UCS of concrete samples with different water-cement ratios (w/c $=0.53,0.54$ and 0.55$)$ and the diameters of 50.8 to $914.4 \mathrm{~mm}$. Figure 12 indicates the results of these laboratory tests and the results predicted by various theories of specimen size effect on strength. As can be seen in this Figure, when sample size increases, its strength reduces. Moreover, the highest determination coefficient value was observed in the FFSEL model for $w / c=0.53$, in the MFSL model for $w / c=0.54$, and in the $\mathrm{H}-\mathrm{B}$ model for $\mathrm{w} / \mathrm{c}=0.55$.

Figure 12. The prediction of uniaxial compressive strength in different diameters for concrete specimens (Blanks \& Mcnamara, 1935) with different water-to-cement ratios (a. $w / c=0.53, b . w / c=0.54$, and $c . w / c=0.55)$ using specimen size effect models of MFSL, FFSEL and H-B.

Hoskins and Horino (1969) investigated specimens of Plaster of Paris with the diameters of 25.3 to $152.3 \mathrm{~mm}$ (Figure 13). The conclusions of statistical investigates on these specimens exhibited that the determination coefficient values of size-effect models were close together.

Figure 13. The prediction of uniaxial compressive strength in different diameters for Plaster of Paris (Hoskins \& Horino, 1969) specimens using specimen size effect models of MFSL, FFSEL and H-B.

The determination coefficient values of the MFSL, FFSEL and Hoek-Brown models for different types of artificial samples are displayed in Table 3. Among different theories on a variety of concrete specimens, the H-B model indicated the high values of the determination coefficient. However, in specimens with large diameters, this model significantly underestimates strength, while, in these diameters, the MFSL model has a better correlation with the results of laboratory tests. 
Table 3. The determination coefficient values $\left(\mathrm{R}^{2}\right)$ and parameters of MFSL, FFSEL and Hoek-Brown models for different types of artificial samples obtained through regression analysis.

\section{Experimental study}

Considering the simultaneous effect of various factors relating to rock material and rock mass, laboratory testing of the effect of one factor on the mechanical properties of rock samples may encounter many errors. The best method of surveying one parameter, without the effect of other parameters, is physical modelling using artificial materials such as concrete (Hoseinie, Aghababaei \& Pourrahimian, 2008).

\subsection{Specimen preparation}

To evaluate the effect of specimen size and grain size on uniaxial compressive strength, three concrete blocks of approximately $500 \mathrm{~mm} \times 500 \mathrm{~mm} \times 500 \mathrm{~mm}$ with three different grain sizes were manufactured. After the curing time (28 days), 84 cylindrical specimens were obtained from blocks using a laboratory drilling machine. According to the recommendation of the International Society of Rock Mechanics (ISRM, 2007), the specimens had the diameters of 56, 68, 72 and $94 \mathrm{~mm}$ and the length-to-diameter ratio of $2.0(\mathrm{~L} / \mathrm{D}=2.0)$.

ACI-211 (1988) and ASTM C33 (2003) standards were utilized for the mixture design of samples and the required grain sizes, respectively. In this research, three plans with different grain sizes were designed. In each of these plans, gravels with the grain sizes of $0-12,0-20$ and $0-25 \mathrm{~mm}$ were used. The mix design used for manufacturing concrete specimens is shown in Table 4.

Table 4. The mix design used for manufacturing concrete specimens. 


\subsection{The results of Uniaxial compressive strength tests}

Uniaxial compressive strength tests were performed on trimmed core samples with the length-to-diameter ratio of 2.0. The stress rate was applied within the limits of 0.5-1.0 $\mathrm{MPa} / \mathrm{s}$. The tests were repeated from a minimum of 3 and a maximum of 10 times, and the results were averaged. Figure 14 shows the results of the uniaxial compressive tests for the concrete samples with a range of diameters and for the grain sizes of $0-12,0-20$ and $0-25 \mathrm{~mm}$. As can be seen in this Figure, similar to the results of the studies by Hawkins (1998) and Masoumi et al. (2015), for the grain sizes of 0-20 and 0-25 mm, uniaxial compressive strength initially increases and then decreases when the diameter of specimens increases. Similar to the results of the studies by Yuki et al. (1995) and Pells (2004), for samples with the grain size of 0-12 mm, the compressive strength of specimens increased with increasing the diameter of specimens.

Figure 14. The average UCS of concrete specimens correlated with the diameter of aggregates with various grain sizes.

The plot of uniaxial compressive strength against specimen diameter for each grain size is separately presented in Figure 15. For samples with the grain size of 0-12 $\mathrm{mm}$, the compressive strength of the specimens 56 to $94 \mathrm{~mm}$ in diameter increased about $10 \%$ with a linear trend. In the case of samples with the grain sizes of $0-20$ and $0-25 \mathrm{~mm}$, the plot indicated ascending-descending behavior. In samples with the grain sizes of 0-20 $\mathrm{mm}$ and the diameters of 56 to $68 \mathrm{~mm}$, compressive strength increased initially about 0.2 $\%$ and then decreased about $19 \%$ in the diameters of 68 to $94 \mathrm{~mm}$. Moreover, strength increased about $9 \%$ in samples with the grain size of $0-25 \mathrm{~mm}$ and the diameters of 56 to $72 \mathrm{~mm}$ but decreased about $30 \%$ in the diameters of 72 to $94 \mathrm{~mm}$. Therefore, an increase in UCS values with increasing sample size was observed for almost all specimens with 
the grain sizes of 0-20 and 0-25 mm, except for the specimens with the diameter of 94 mm (Figure 15).

Figure 15. The average UCS of concrete specimens correlated with the diameter of aggregates with the grain sizes of 0-12, 0-20 and 0-25 mm.

Figures 16, 17 and 18 display results of the prediction of uniaxial compressive strength in different diameters for concrete specimens with different grain sizes using specimen size effect models of MFSL, SEL-I and H-B. In the case of concrete with the grain size of 0-12 mm, MFSL (using Equation 4) and SEL-I (using Equation 7) models confirmed the ascending trend of strength. In addition, in specimens with the grain sizes of 0-20 and 0-25 mm, the MFSL model indicated highest determination coefficient values ( $R^{2}=0.72$ and $R^{2}=0.47$ respectively). Table 5 presents the results of statistical analysis. As can be seen in this table, determination coefficient values of different size effect models decrease with increasing grain size.

Figure 16. The prediction of uniaxial compressive strength in different diameters for concrete specimens with grain sizes of 0-12 mm using the specimen size effect models of MFSL, SEL-I and H-B.

Figure 17. The prediction of uniaxial compressive strength in different diameters for concrete specimens with the grain sizes of 0-20 mm using specimen size effect models of MFSL, SEL-I and H-B.

Figure 18. The prediction of uniaxial compressive strength in different diameters for concrete specimens with the grain sizes of 0-25 mm using specimen size effect models of MFSL, SEL-I and H-B.

Table 5. The determination coefficient values $\left(\mathrm{R}^{2}\right)$ and parameters of MFSL, SEL-I and Hoek-Brown models obtained by regression analysis in the experimental studies conducted on the concrete specimens. 


\section{Discussion}

To study the effect of specimen size on the uniaxial compressive strength of rock and concrete specimens using statistical methods, the SEL-I model was utilized for rock samples, because there was no large notch in these specimens. Moreover, the fractal fracture size-effect model (FFSEL) was used for artificial samples with large notches. Non-linear regression analysis of igneous hard rocks showed that there was a better agreement between the outputs of the multifractal scaling model and the SEL-I model and the results of previous laboratory tests. The Hoek and Brown empirical model showed high determination coefficient values for artificial specimens. However, this model was conservative for samples with large diameters, while, in these diameters, the multi-fractal scaling model indicated a good correlation with experimental data. A significant advantage of the multi-fractal scaling model over other models was its ability to estimate the realistic strength of samples with large diameters. All available models presented approximately the same determination coefficient values for artificial samples. It appears that any scale relationship is highly material dependent.

Considering the previously published data presented in this research, it is clear that determination coefficient values were low due to one or more of the following issues: (a) the testing method, (b) specimen preparation and (c) anisotropy (the effect of grain size and loading conditions with respect to anisotropy orientation).

The testing method and apparatus specifications lead to some variations in results. These variations can be due to a high sensitivity to testing methodologies such as test rig stiffness, loading rate, the effect of boundary conditions including loading plate friction, specimen end preparation (consisting of flatness, perpendicularity and smoothness), and the influence of capping materials, if used. These factors have a significant influence on the strength of specimens with small diameters, where stress concentrations lead to a 
significant effect on specimen strength due to the poor preparation of the specimen end. In addition, the characteristics of discontinuities such as orientation, spacing, dip, filling, aperture, roughness, and waviness cause variations in the results of experimental tests.

The results of uniaxial compressive strength tests for the grain sizes of 0-20 and 0-25 $\mathrm{mm}$ in the experimental study were similar to those reported by Hawkins (1998) and Masoumi et al. (2015), where uniaxial compressive strength increased initially and then decreased as the specimen diameter increased. In other words, an increase in UCS values with increasing sample size was obtained for almost all specimens, except for specimen with the diameter of $94 \mathrm{~mm}$. This conclusion can be attributed to the fact that the specimens with the diameter of $94 \mathrm{~mm}$ may be considerably weaker than other specimens due to the increasing amount of inherent weakness agents such as porosity and microfissures. In the case of specimens with small diameters, structural flaws were less likely to appear, new cracks were created in the sample at the moment of failure, and the sample eventually ruptured with the propagation of these cracks. By increasing sample size, the possibility of the appearance of micro-cracks and pores in the sample increased. Thus, the structural flaws acted as weak points and made the specimen rupture easily when the sample was placed under loading. When a sample is placed under pressure, micro-cracks in the sample propagate, link together, cause a poor plate in the sample, and eventually make the sample fracture.

The results of the present study on the effect of grain size on compressive strength showed that an increase in grain size decreases the compressive strength of the specimen $94 \mathrm{~mm}$ in diameter. Regarding the samples made of a concrete containing a smaller grain size $(0-12 \mathrm{~mm})$ with the diameters of 56,68 , and $72 \mathrm{~mm}$, however, compressive strength is lower than that of the samples made of a concrete containing a larger grain sizes (0-20 $\mathrm{mm}$ or $0-25 \mathrm{~mm})$. In addition, the results indicated that compressive strength increases 
with increasing sample size for the grain size of 0-12 $\mathrm{mm}$. Therefore, the concrete samples $94 \mathrm{~mm}$ in diameter containing a larger grain content and a larger mortar volume, exhibit higher compressive strengths than those 56,68 , and $72 \mathrm{~mm}$ in diameter.

Results of the statistical analysis showed multi-fractal scaling model and the specimen size-effect model using the fracture energy theory confirm the ascending trend of the strength of concrete specimens with the grain size of 0-12 mm. In specimens with the grain size of $0-20$ and $0-25 \mathrm{~mm}$, the multi-fractal scaling model indicated the highest determination coefficient values.

\section{Conclusions}

In this study, the effect of specimen size on the uniaxial compressive strength of igneous hard rocks and concrete specimens was investigated considering the literature and using size effect models and statistical analyses. Results of the investigations on igneous hard rocks using non-linear regression analysis showed a better agreement between the results of previous laboratory tests and those of the multifractal scaling model and the specimen size-effect model using the fracture energy theory. In addition, in concrete specimens, the Hoek-Brown model indicated high values of the determination coefficient. However, this model was conservative in specimens with large diameters, while the multifractal scaling model showed a good correlation with experimental data in these diameters. The results of the experimental studies on concrete specimens with the grain size of 0-12, were similar to the results of Yuki et al. (1995) and Pells (2004). In addition, it was shown that in grain sizes of 0-20 and 0-25 mm, similar to the results of Hawkins (1998) and Masoumi et al. (2015), as the specimen diameter increases, uniaxial compressive strength first increases and then decreases. Additionally, statistical investigations showed that the multi-fractal scaling model and the specimen size-effect model using the fracture energy theory confirm the increasing trend of UCS in fine- 
grained specimens. In coarse-grained specimens, the multi-fractal scaling model indicated the highest determination coefficient values. The results of the present study confirmed the grain size effect on the evaluations of specimen size-effect models, where determination coefficient values of different models reduce with increasing the grain size. The results of this study can be utilized to design engineering projects at different scales such as structures on or within a rock mass, large underground structures constructed for transferring water and storing oil and gas, underground power plants, and radioactive waste repositories. The results can also be used to estimate the strength of pillars for supporting underground openings with greater sizes than those of laboratory samples.

\section{Disclosure statement}

No potential conflict of interest was reported by the authors.

\section{References}

ACI Committee. (1988). Measurement of properties of fiber reinforced concrete. ACI Materials Journal, 85(6), 583-593.

Adey, R. A., \& Pusch, R. (1999). Scale dependency in rock strength. Engineering Geology, 53, 251-258.

Andreev, G. E. (1991a). A review of the Brazilian test for rock tensile strength determination. Part I: Calculation formula. Mining Science and Technology, 13(3), 445-456.

Andreev, G. E. (1991b). A review of the Brazilian test for rock tensile strength determination. Part II: Contact conditions. Mining Science and Technology, 13(3), 457-465.

ASTM. (2003). Standard specification for concrete aggregates- C33-03. Annual Book of ASTM Standards, 4(2).

Aubertin, M., Li, L., \& Simon, R. (2000). A multiaxial stress criterion for short and long term strength of isotropic rock media. International Journal of Rock Mechanics and Mining Sciences, 37(8), 1169-1193. 
Baecher, G. B., \& Einstein, H. H. (1981). Size effect in rock testing. Geophysical Research Letters, 8(7), 671-674.

Bazant, Z. P. (1997). Scaling of quasibrittle fracture: Hypotheses of invasive and lacunar fractality, their critique and Weibull connection. International Journal of Fracture, 83(1), 41-65.

Bazant, Z. P. (2004). Scaling theory for quasibrittle structural failure. Proceedings of the National Academy of Sciences, USA, 101(37), 13400-13407.

Bazant, Z. P., \& ASCE, F. (1984). Size effect in blunt fracture: Concrete, rock, metal. Journal of Engineering Mechanics, 110(4), 518-535.

Bazant, Z. P., ASCE, F., Vorechovsky, M., \& Novak, D. (2007). Asymptotic prediction of energetic-statistical size-effect from deterministic finite-element solutions. Journal of Engineering Mechanics, 133(2), 153-162.

Bazant, Z. P., \& Chen, E. P. (1997). Scaling of structural failure. Applied Mechanics Reviews, 50(10), 593-627.

Bazant, Z. P., Gettu, R., Jirasek, M., Barr, B. I. G., Carol, I., Carpinteri, A., ... Vliet, M. R. A. (2004). RILEM TC QFS, Quasibrittle fracture scaling and size effect-Final report. Materials and Structures, 37, 547-568.

Bazant, Z. P., Lin, F. B., \& Lippmann, H. (1993). Fracture energy release and size effect in borehole breakout. International Journal for Numerical and Analytical Methods in Geomechanics, 17, 1-14.

Bazant, Z. P., \& Oh, B. H. (1983). Crack band theory for fracture of concrete. Materials and Structures, 16, 155-177.

Bazant, Z. P., \& Pang, S. D. (2007). Activation energy based extreme value statistics and size effect in brittle and quasibrittle fracture. Journal of the Mechanics and Physics of Solids, 55, 91-131.

Bazant, Z. P., \& Planas, J. (1998). Fracture and size effect in concrete and other quasibrittle materials. CRC Press.

Bazant, Z. P., Vorechovsky, M., \& Novak, D. (2007). Energetic statistical size effect simulated by SFEM with stratified sampling and crack band model. International Journal of Numerical Methods Engineering, 71, 1297-1320.

Bazant, Z. P., \& Yu, Q. (2009). Universal size effect law and effect of crack depth on quasi-brittle structure strength. Journal of Engineering Mechanics, 135(2), 78-84.

Bieniawski, Z. T. (1968). The effect of specimen size on compressive strength of coal. International Journal of Rock Mechanics and Mining Sciences, 5, 325-335. 
Bieniawski, Z. T. (1975). The point load test in geotechnical practice. Eng. Geol, 9, 1-11.

Blanks, R. F., \& Mcnamara, C. C. (1935). Mass concrete tests in large cylinders. Journal of American Concrete Institute, 31,280-303.

Butenuth, C. (1997). Comparison of tensile strength values of rocks determined by point load and direct tension tests. Rock Mechanics and Rock Engineering, 30(1), 6572.

Canakci, H., \& Pala, M. (2007). Tensile strength of basalt from a neural network. Engineering Geology, 94(1-2), 10-18.

Carpinteri, A. (1994). Fractal nature of material microstructure and size effects on apparent mechanical properties. Mechanics of Materials, 18, 89-101.

Carpinteri, A., Chiaia, B., \& Ferro, G. (1995). Size effects on nominal tensile strength of concrete structures: multifractality of material ligaments and dimensional transition from order to disorder. Materials and Structures, 28(6), 311-317.

Carpinteri, A., Ferro, G., \& Monetto, I. (1999). Scale effects in uniaxially compressed concrete Specimens. Magazine of Concrete Research, 51(3), 217-225.

Carpinteri, A., \& Mainardi, F. (1997). Fractals and fractional calculus in continuum mechanics. Springer.

Darlington, W. J., \& Ranjith, P. G. (2011). The effect of specimen size on strength and other properties in laboratory testing of rock and rock-like cementitious brittle materials. Rock Mechanics and Rock Engineering, 44(5), 513-529.

Elices, M., \& Rocco, C. (1999). Size effect and boundary conditions in Brazilian test: Theoretical analysis. Materials and Structures, 32(6), 437-444.

Forbes, M., Masoumi, H., Saydam, S., \& Hagan, P. (2015). Investigation into the effect of length to diameter ratio on the point load strength index of Gosford sandstone. In 49th U.S. Rock Mechanics/Geomechanics Symposium American Rock Mechanics Association, San Francisco.

Greminger, M. (1982). Experimental studies of the influence of rock anisotropy and size and shape effects in point-load testing. International Journal of Rock Mechanics and Mining Sciences, 19, 241-246.

Griffith, A. A. (1924). The theory of rupture. In 1st International Congress for applied mechanics, Delft, Netherlands, 55-63.

Hawkins, A. B. (1998). Aspects of rock strength. Bulletin of Engineering Geology and the Environment, 57, 17-30. 
Hoek, E. (2000). Rock engineering course notes by Evert Hoek. website: http://www.rocscience.com/education/hoeks corner

Hoek, E., \& Brown, E. T. (1980). Underground excavations in rock. Transactions of the Institution of Mining and Metallurgy, London.

Hoseinie, S. H., Aghababaei, H., \& Pourrahimian, Y. (2008). Development of a new classification system for assessing of rock mass drillability index (RDi). International Journal of Rock Mechanics and Mining Sciences, 45, 1-10.

Hoskins, J. R., \& Horino, F. G. (1969). Influence of spherical head size and specimen diameters on the uniaxial compressive strength of rocks. US Department of the Interior, Bureau of Mines, Washington.

Hunt, D. D. (1973). The influence of confining pressure on size effect (Master' s thesis). Massachusetts Institute of Technology, Cambridge.

ISRM. (2007). The complete ISRM suggested methods for rock characterization, testing and monitoring: 1974-2006 (ed.). Ulusay, R., \& Hudson, J. A., Suggested methods prepared by the commission on testing methods. International Society for Rock Mechanics, Compilation Arranged by the ISRM Turkish National Group, Ankara, Turkey.

Jackson, R., \& Lau, J. S. O. (1990). The effect of specimen size on the laboratory mechanical properties of Lac du Bonnet grey granite. Proceedings of the first international workshop on scale effects in rock masses, Loen, 165-174.

Manouchehrian, A., Sharifzadeh, M., \& Hamidzadeh Moghadam, R. (2012). Application of artificial neural networks and multivariate statistics to estimate UCS using textural characteristics. International Journal of Mining Science and Technology, 22, 229-236.

Masoumi, H., Douglas, K. J., \& Russell, A. R. (2016). A bounding surface plasticity model for intact rock exhibiting size-dependent behavior. Rock Mechanics and Rock Engineering, 49, 47-62.

Masoumi, H., Roshan, H., \& Hagan, P. C. (2017). Size-dependent Hoek-Brown failure criterion. International Journal of Geomechanics, 17(2), 1-12.

Masoumi, H., Saydam, S., \& Hagan, P. C. (2015). Unified Size-Effect Law for Intact Rock. International Journal of Geomechanics, 16(2), 1-15. 
Medhurst, T. P., \& Brown, E. T. (1998). A study of the mechanical behavior of coal for pillar design. International Journal of Rock Mechanics and Mining Sciences, 35(8), 1087-1105.

Mogi, K. (1962). The influence of dimensions of specimens on the fracture strength of rocks. Bulletin of the Earthquake Research Institute, 40, 175-185.

Natau, O. P., Froehlich, B. O., \& Mutschler, T. H. O. (1983). Recent developments of the largescale triaxial test. Fifth International Congress on Rock Mechanics, Melbourne, 65-74.

Nishimatsu, Y., Yamaguchi, U., Motosugi, K., \& Morita, M. (1969). The size effect and experimental error of the strength of rocks. Journal of the Society of Materials Science, 18, 1019-1025.

Ovalle, C., Frossard, E., Dano, C., Hu, W., Maiolino, S., \& Hicher, P. Y. (2014). The effect of size on the strength of coarse rock aggregates and large rockfill samples through experimental data. Acta Mechanica, 225, 2199-2216.

Pells, P. J. N. (2004). On the absence of size effects for substance strength of Hawkesbury Sandstone. Australian Geomechanics Journal, 39, 79-83.

Poulsen, B. A. \& Adhikary, D. P. (2013). A numerical study of the scale effect in coal strength. International Journal of Rock Mechanics and Mining Sciences, 63, 6271.

Pretorius, J. P. G. \& Se, M. (1972). Weakness correlation and the size effect in rock strength tests. Journal- South African Institute of Mining and Metallurgy, 12, 322327.

Rezaei, H. (2015). Laboratory study of grain size effect and size effect of specimen on the mechanical properties and rock failure behaviour (Master' $s$ thesis). Isfahan University of Technology, Isfahan.

Singh, M. M., \& Huck, P. J. (1972). Large scale triaxial tests on rock. In the 14th US Symposium Rock Mechanics., Pennsylvania State University, 35-60.

Thuro, K., Plinninger, R. J., Zah, S., \& Schutz, S. (2001a). Scale effects in rock strength properties. Part1: Unconfined compressive test and Brazilian test. Rock Mechanics-A Challenge for Society, ISRM, Espoo, 169-174.

Thuro, K., Plinninger, R. J., Zah, S., \& Schutz, S. (2001b). Scale effect in rock strength properties. Part 2: Point load test and point load strength index. Rock MechanicsA Challenge for Society, Zeitlinger, Switzerland, 175-180. 
Weibull, W. (1939). A statistical theory of the strength of materials. Ingeniors vetenskaps akademiens handlingar, 151, 1-29.

Weibull, W. (1951). A statistical distribution of function of wide applicability. Journal of Applied Mechanics, 18, 293-297.

Yoshinaka, R., Osada, M., Park, H., Sasaki, T., \& Sasaki, K. (2008). Practical determination of mechanical design parameters of intact rock considering scale effect. Engineering Geology, 96(3-4), 173-186.

Yuki, N., Aoto, S., Yoshinaka, R., Yoshihiro, O., \& Terada, M. (1995). The scale and creep effect on the strength of welded tuff. In International workshop on rock foundation, Balkema, Tokyo.

Zhang, Q., Zhu, H., Zhang, L., \& Ding, X. (2011). Study of scale effect on intact rock strength using particle flow modelling. International Journal of Rock Mechanics and Mining Sciences, 48, 1320-1328. 


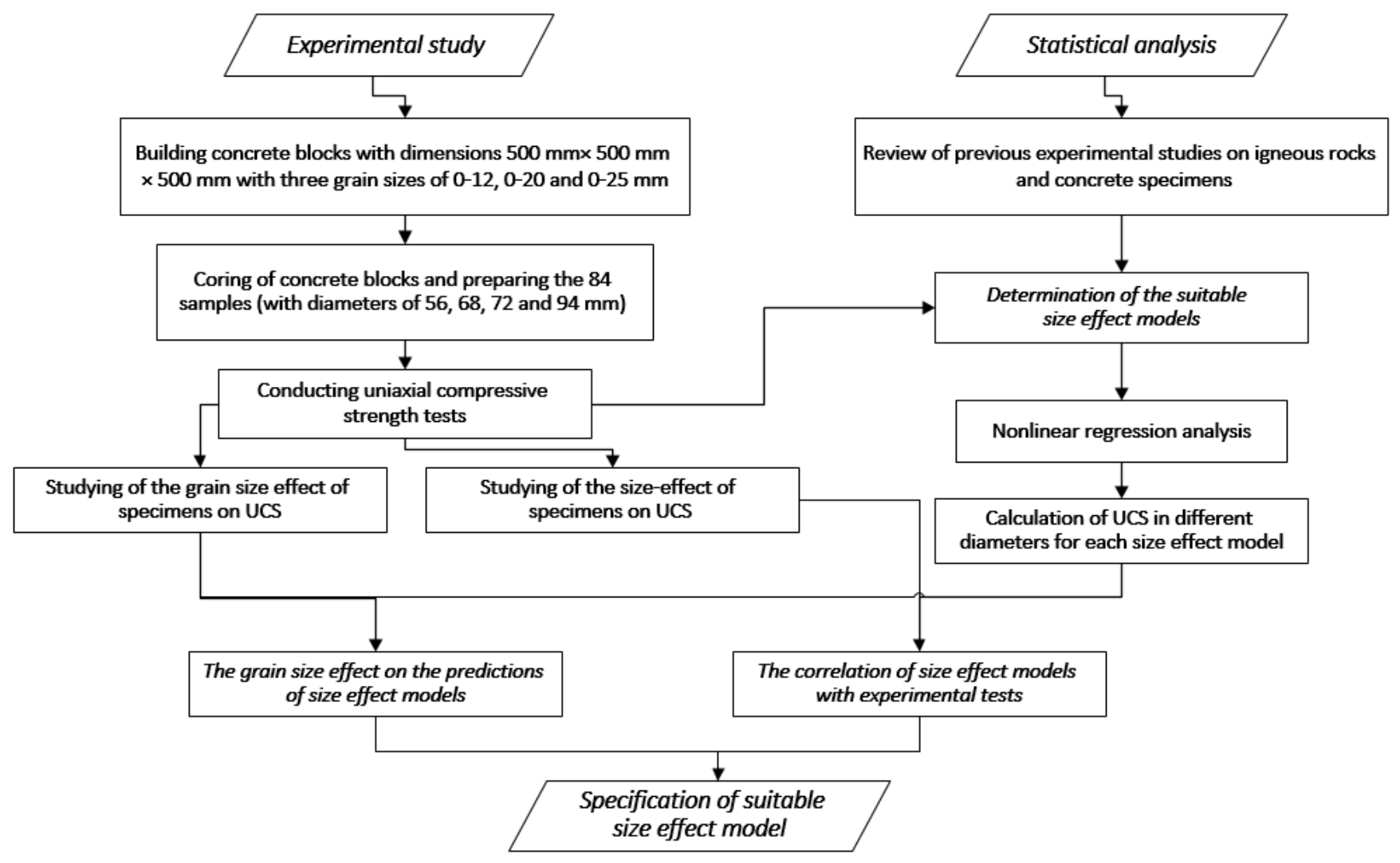

Figure 1. Procedure for assessing specimen size-effect and grain size-effect on uniaxial compressive strength applied in this research. 


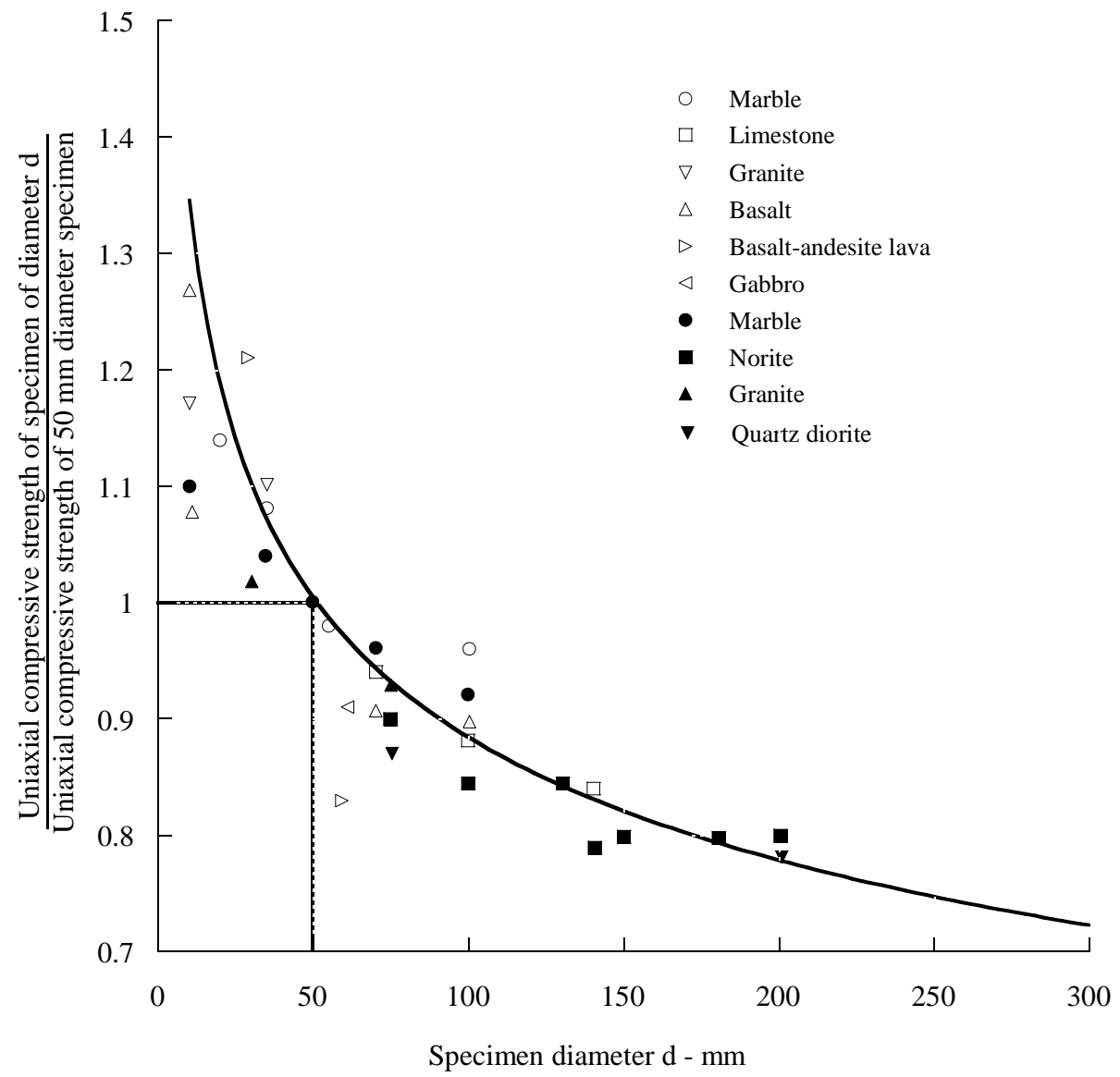

Figure 2. The effect of specimen size on the uniaxial compressive strength of intact rocks (Hoek, 2000).

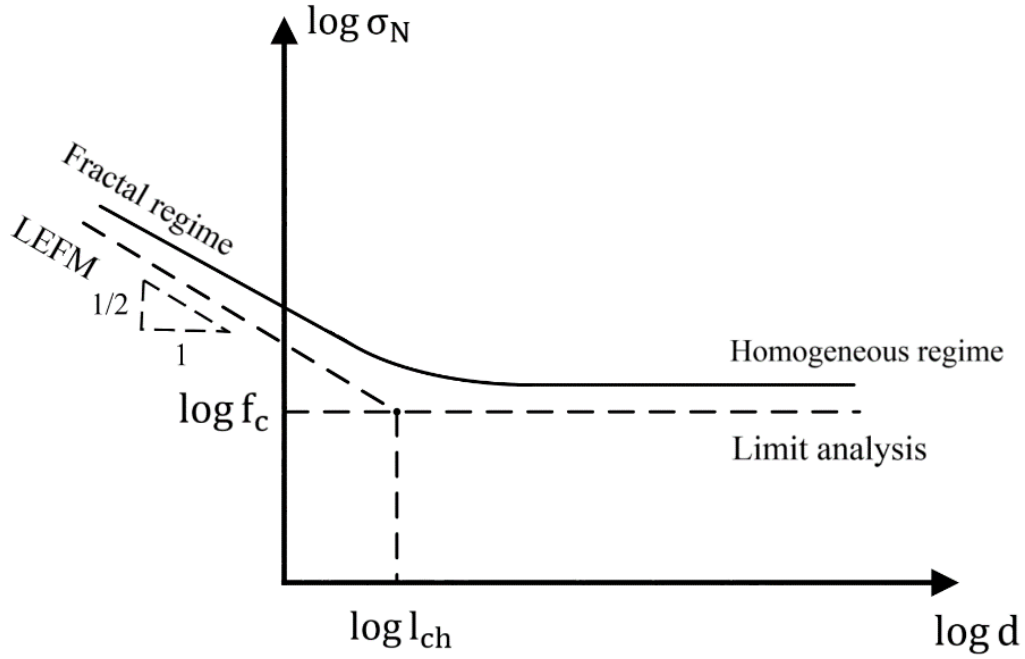

Figure 3. Scale effects according to the multifractal scaling model (Carpinteri et al., 1999). 


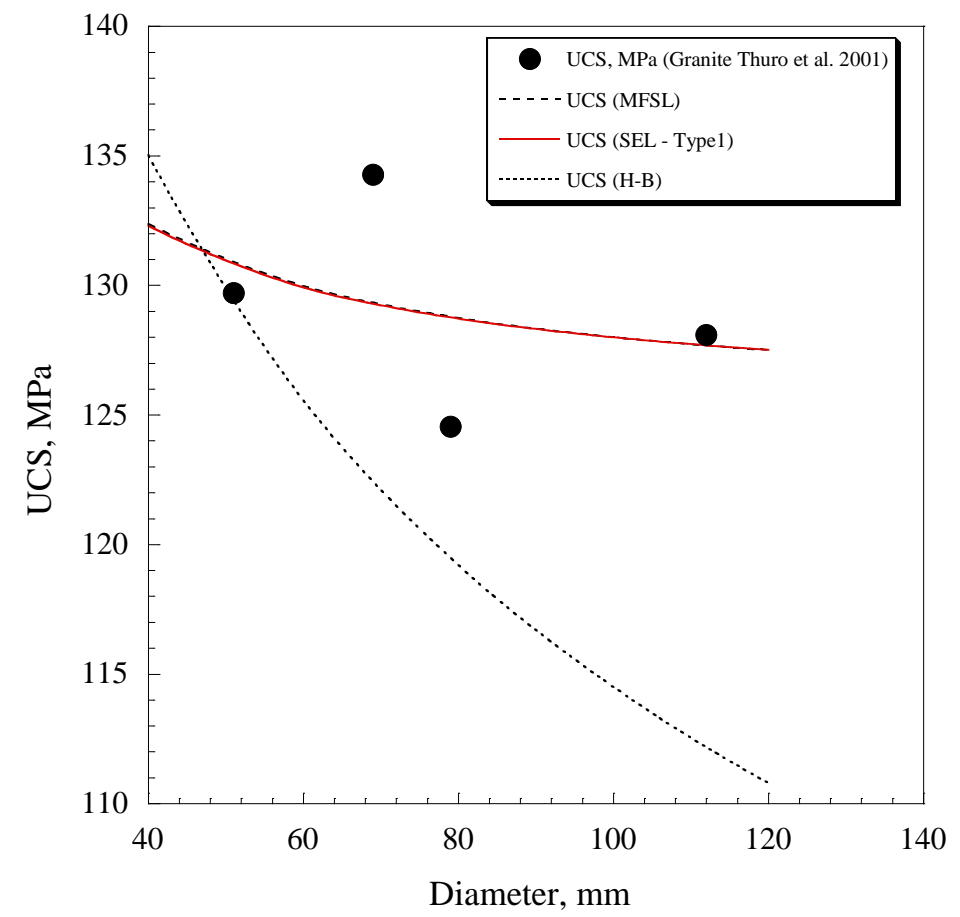

Figure 4. The prediction of uniaxial compressive strength in different diameters for granite specimens (Thuro et al., 2001a) using specimen size effect models of MFSL, SEL-I and H-B.

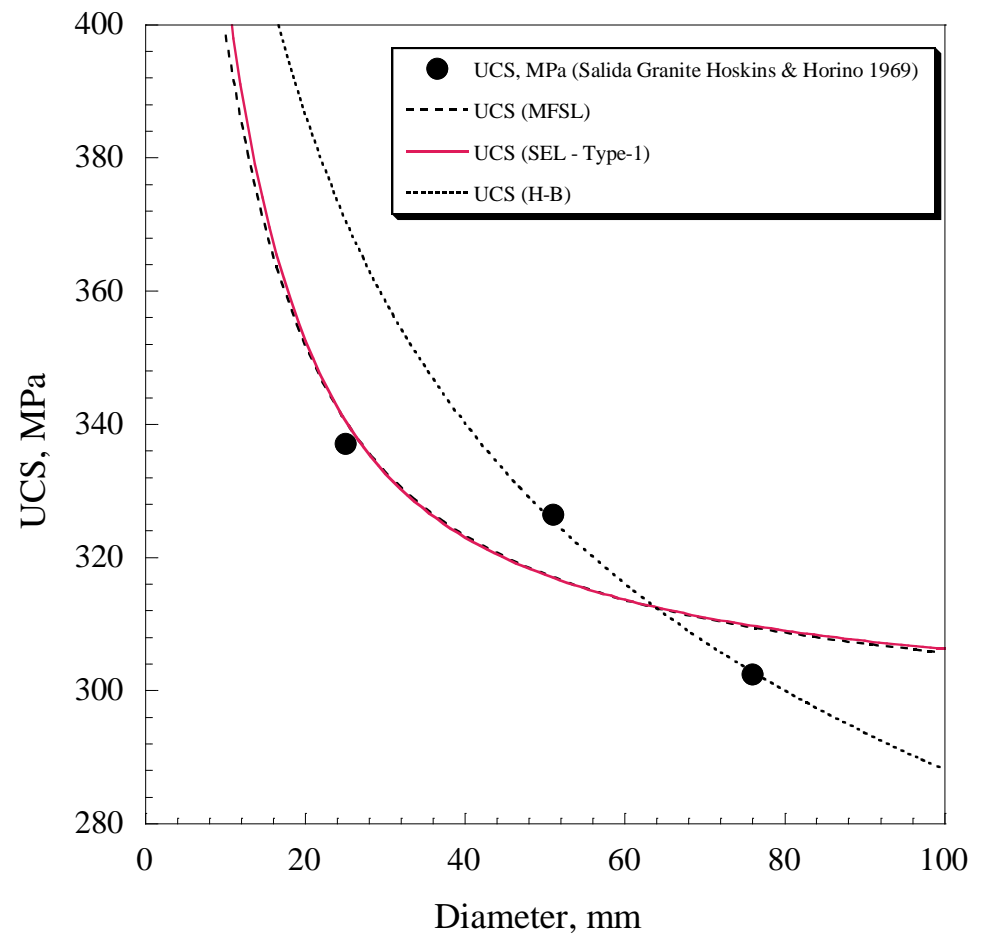

Figure 5. The prediction of uniaxial compressive strength in different diameters for Salida granite (Hoskins \& Horino, 1969) specimens using the specimen size effect models of MFSL, SEL-I and H-B. 


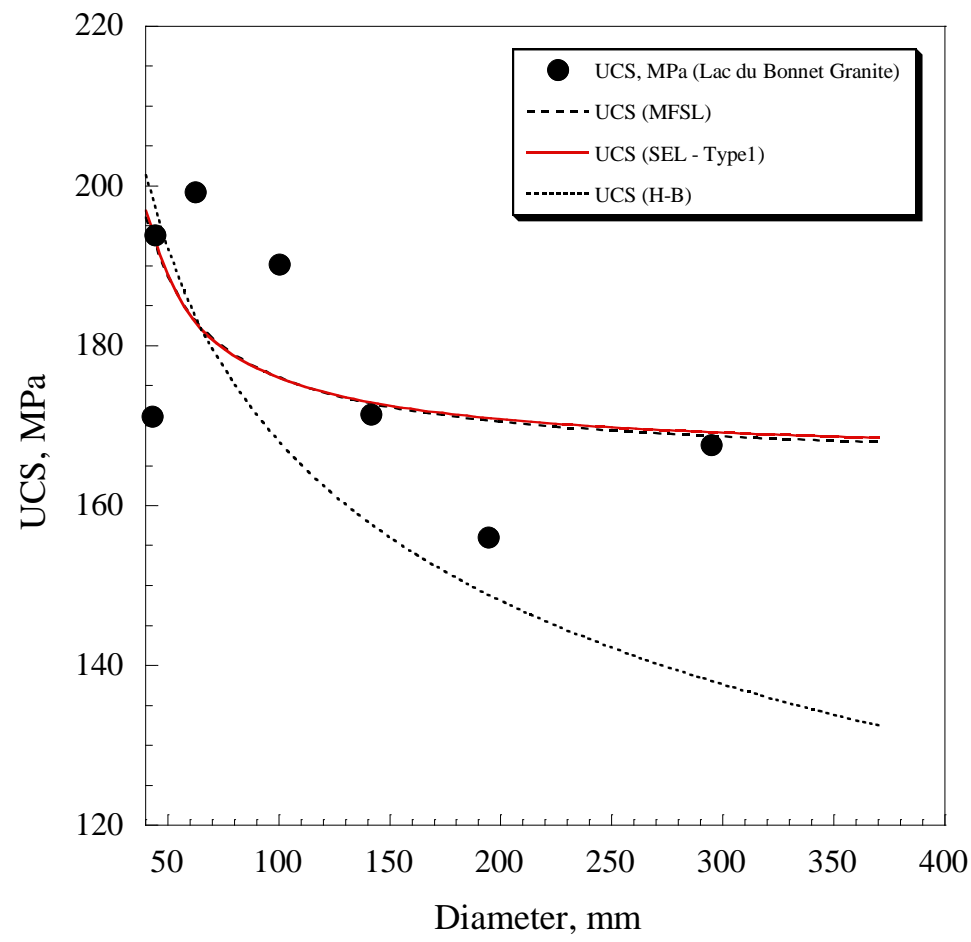

Figure 6. The prediction of uniaxial compressive strength in different diameters for Lac du Bonnet granite (Jackson \& Lau, 1990) specimens using the specimen size effect models of MFSL, SEL-I and H-B.

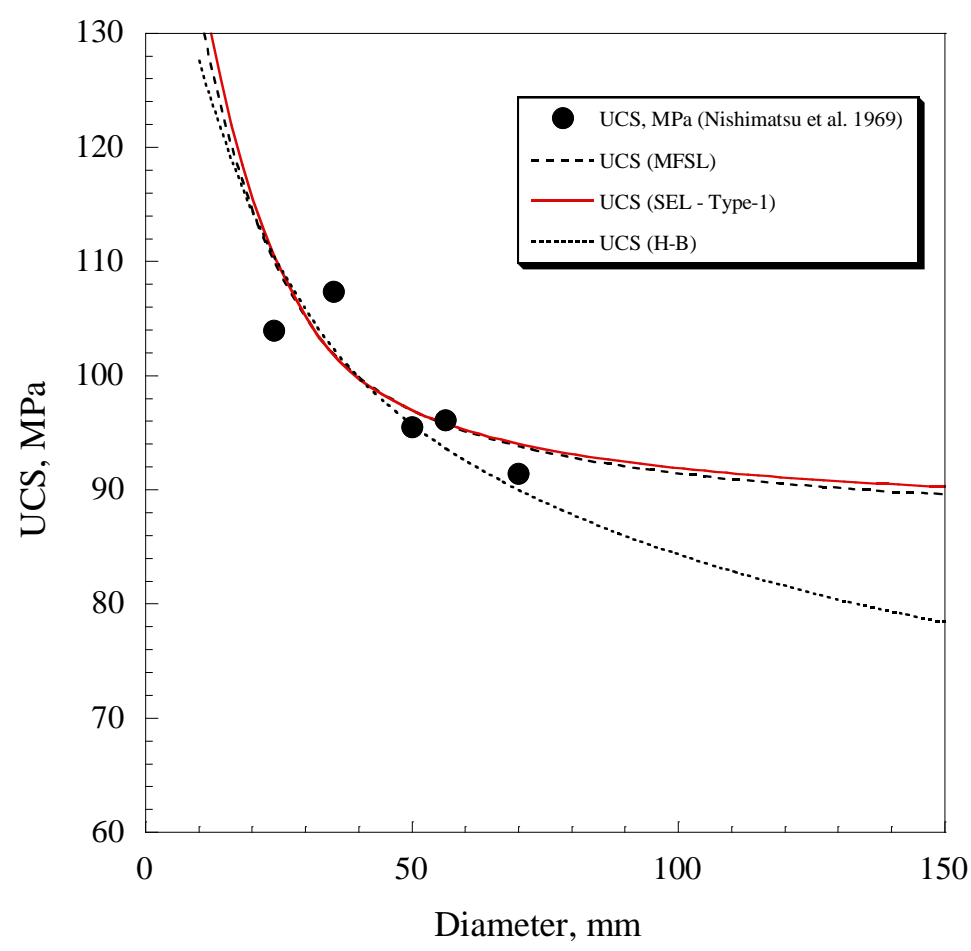

Figure 7. The prediction of uniaxial compressive strength in different diameters for Saajome andesite (Nishimatsu et al., 1969) specimens using specimen size effect models of MFSL, SEL-I and H-B. 


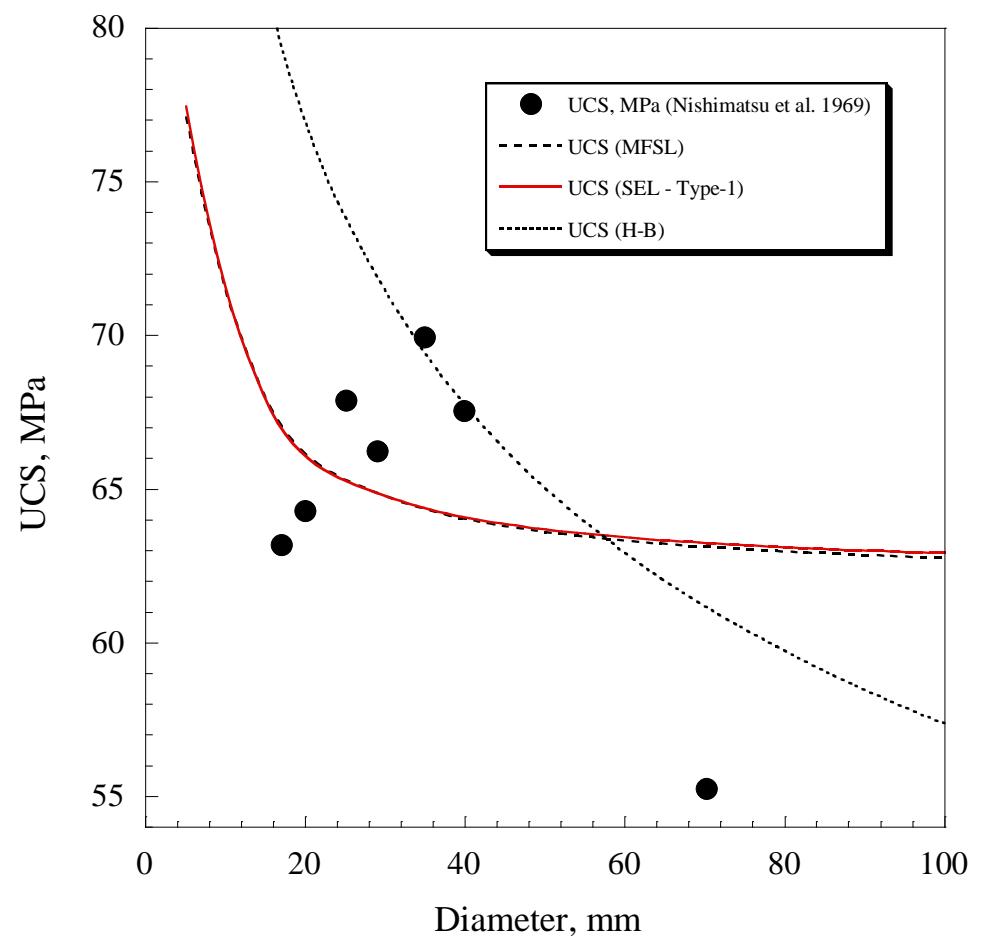

Figure 8. The prediction of uniaxial compressive strength in different diameters for Ogino tuff (Nishimatsu et al., 1969) specimens using specimen size effect models of MFSL, SEL-I and H-B.

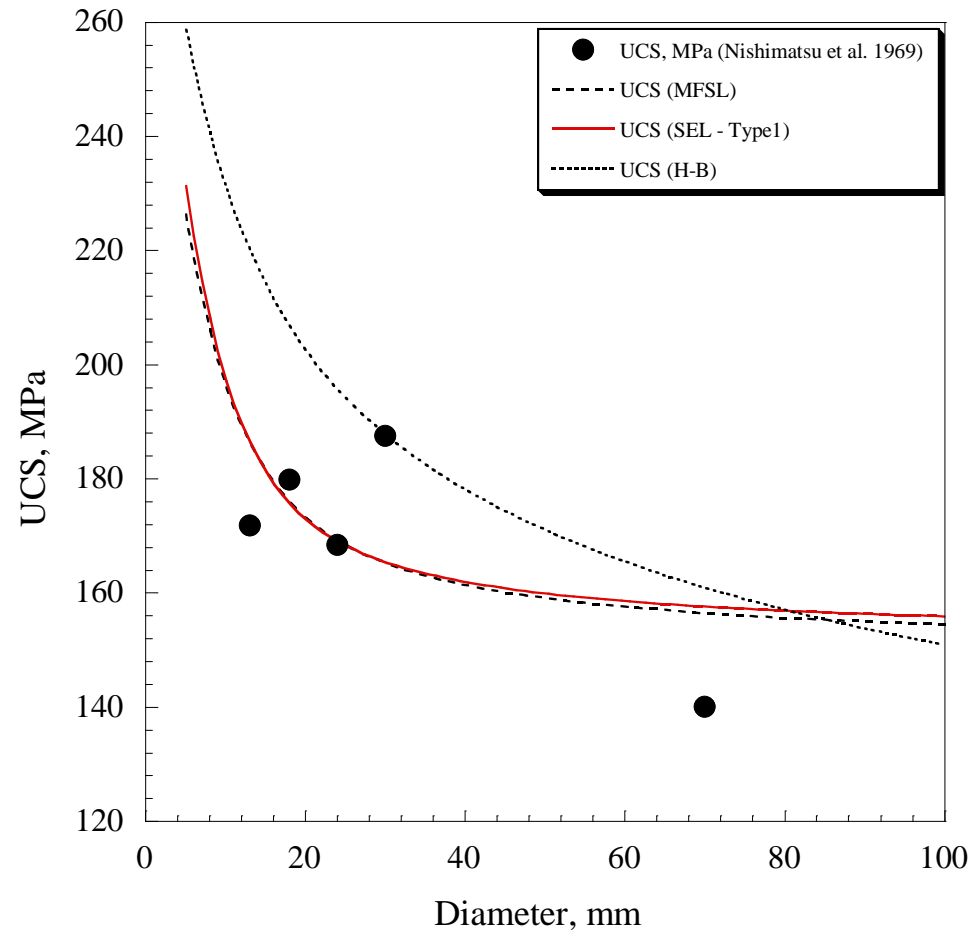

Figure 9. The prediction of uniaxial compressive strength in different diameters for Inada granite (Nishimatsu et al., 1969) specimens using specimen size effect models of MFSL, SEL-I and H-B. 


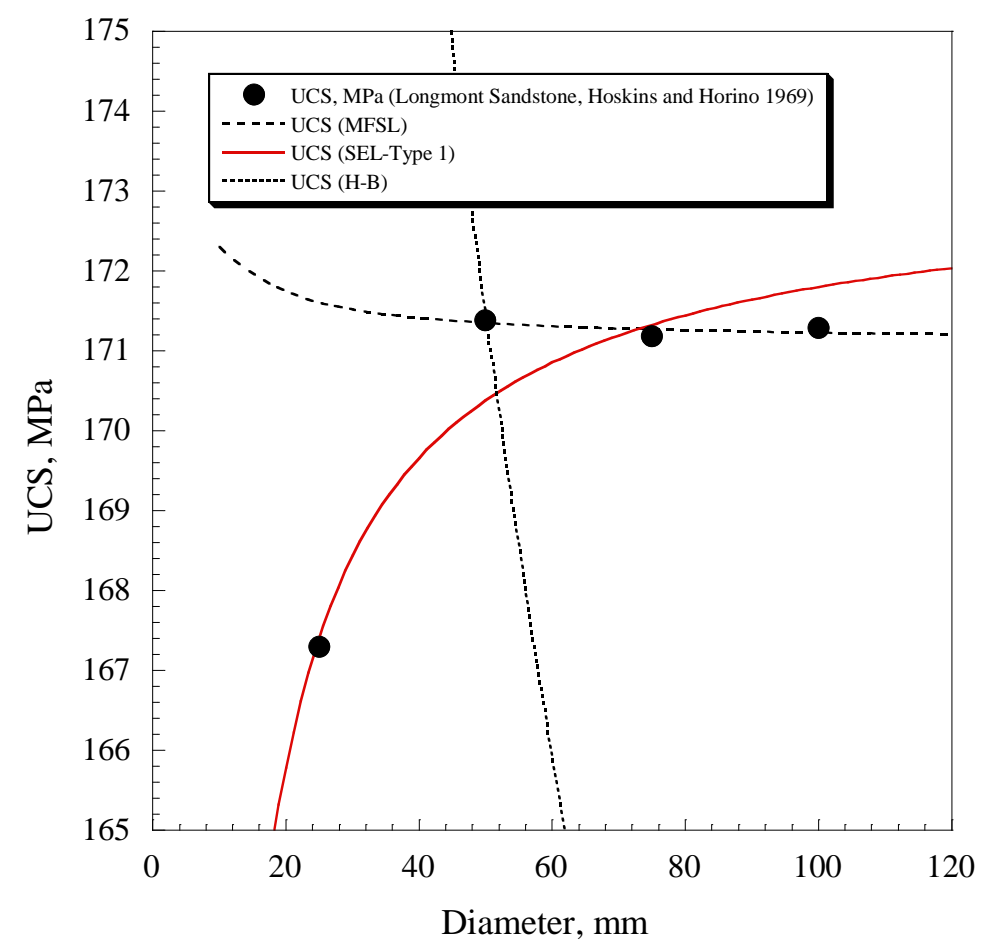

Figure 10. The prediction of uniaxial compressive strength in different diameters for Longmont sandstone (Hoskins \& Horino, 1969) specimens using specimen size effect models of MFSL, SEL-I and H-B. The MFSL and SEL-I lines were only fitted to the data> $50 \mathrm{~mm}$.

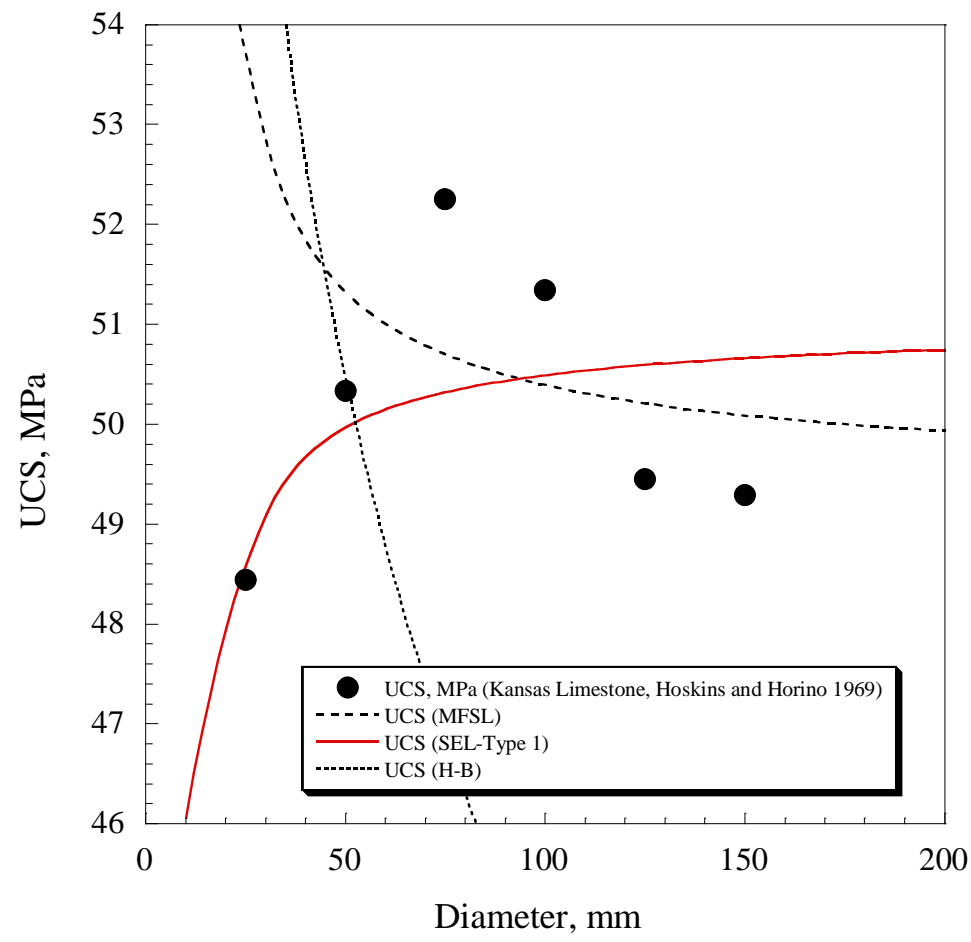

Figure 11. The prediction of uniaxial compressive strength in different diameters for Kansas limestone (Hoskins \& Horino, 1969) specimens using specimen size effect models of MFSL, SEL-I and H-B. The MFSL and SEL-I lines were only fitted to the data $>50 \mathrm{~mm}$. 

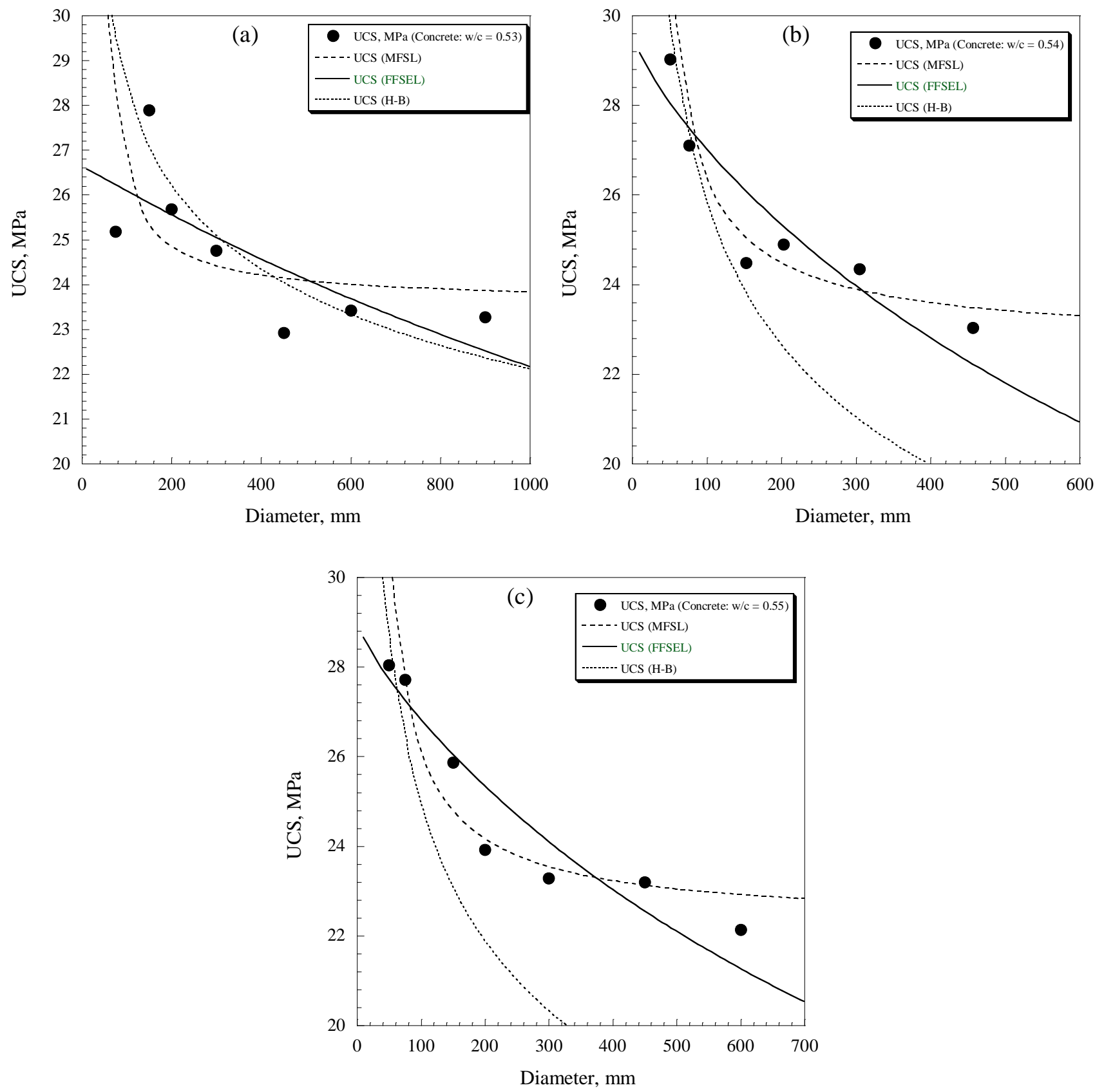

Figure 12. The prediction of uniaxial compressive strength in different diameters for concrete specimens (Blanks \& Mcnamara, 1935) with different water-to-cement ratios $(\mathrm{a} . \mathrm{w} / \mathrm{c}=0.53, \mathrm{~b} . \mathrm{w} / \mathrm{c}=$ 0.54 , and $\mathrm{c} . \mathrm{w} / \mathrm{c}=0.55)$ using specimen size effect models of MFSL, FFSEL and H-B. 


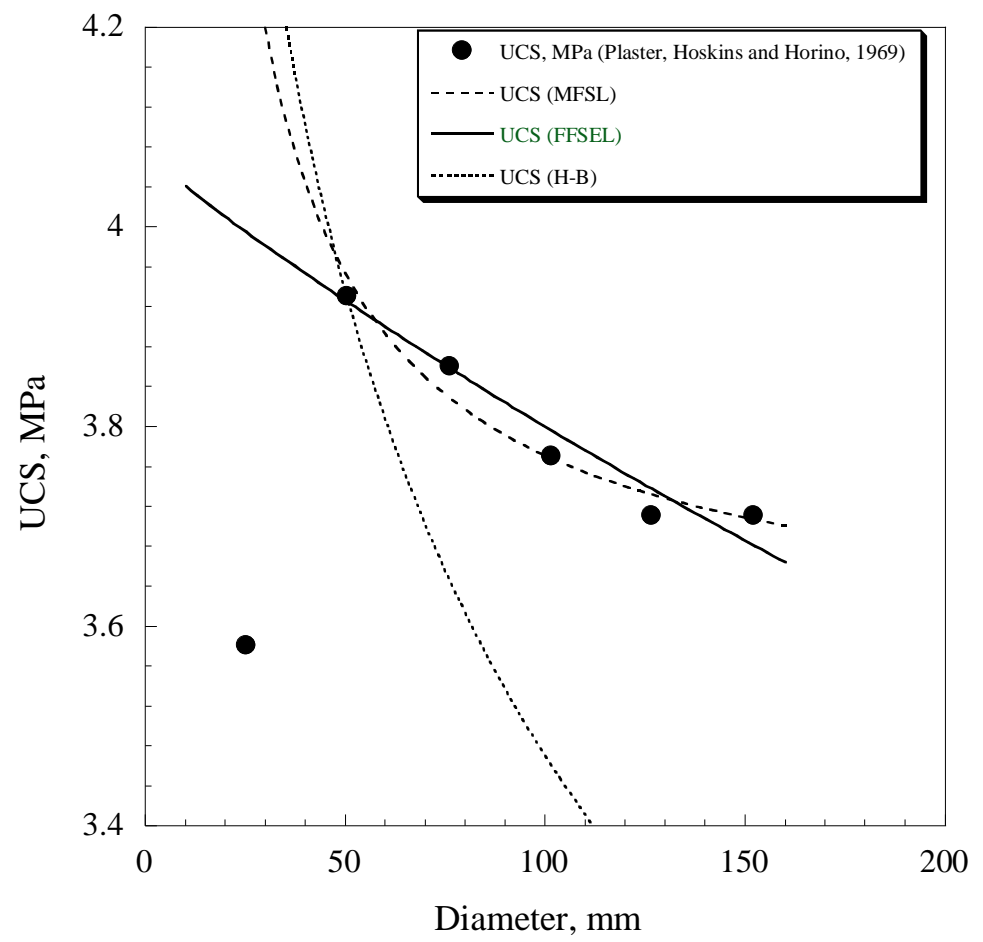

Figure 13. The prediction of uniaxial compressive strength in different diameters for Plaster of Paris (Hoskins \& Horino, 1969) specimens using specimen size effect models of MFSL, FFSEL and H-B.

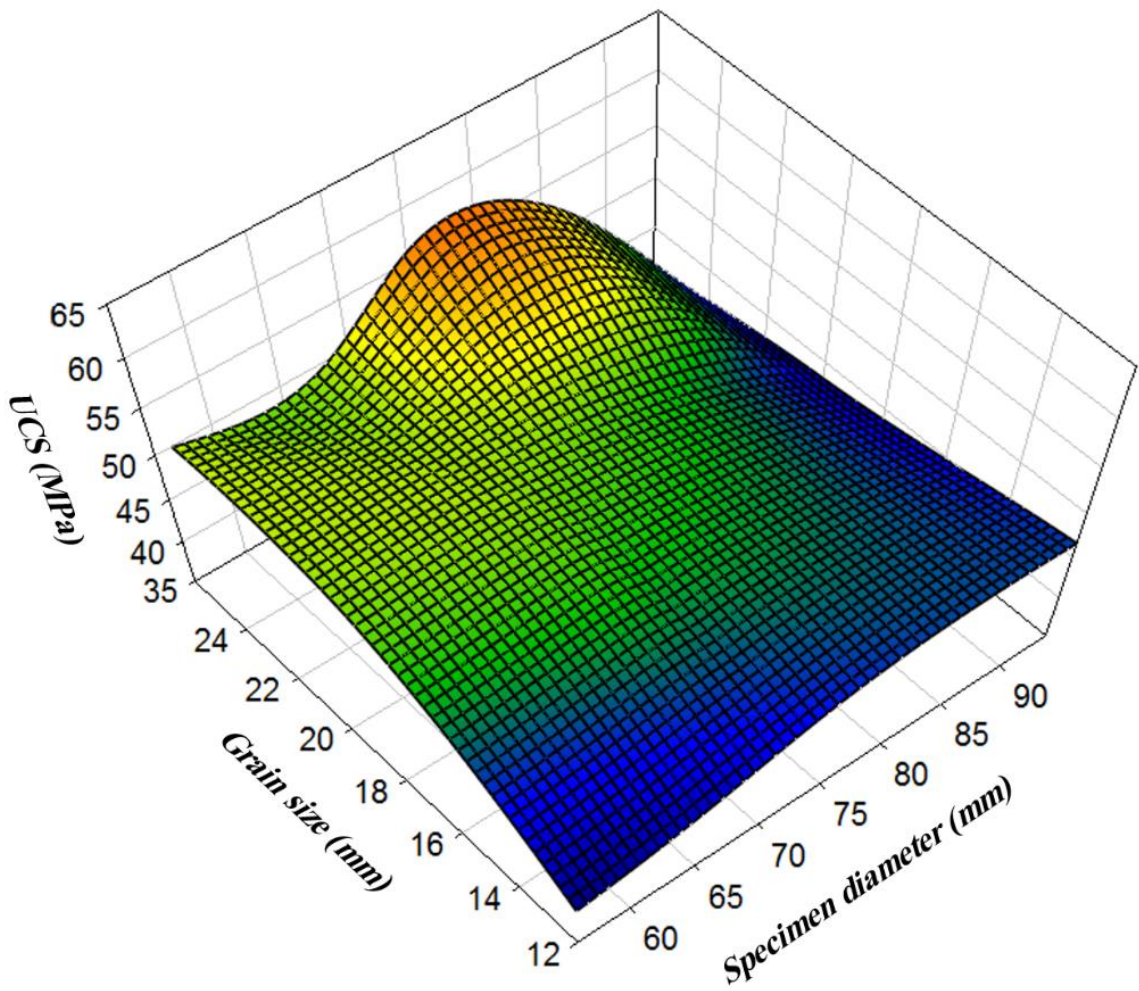

Figure 14. The average UCS of concrete specimens correlated with the diameter of aggregates with various grain sizes. 


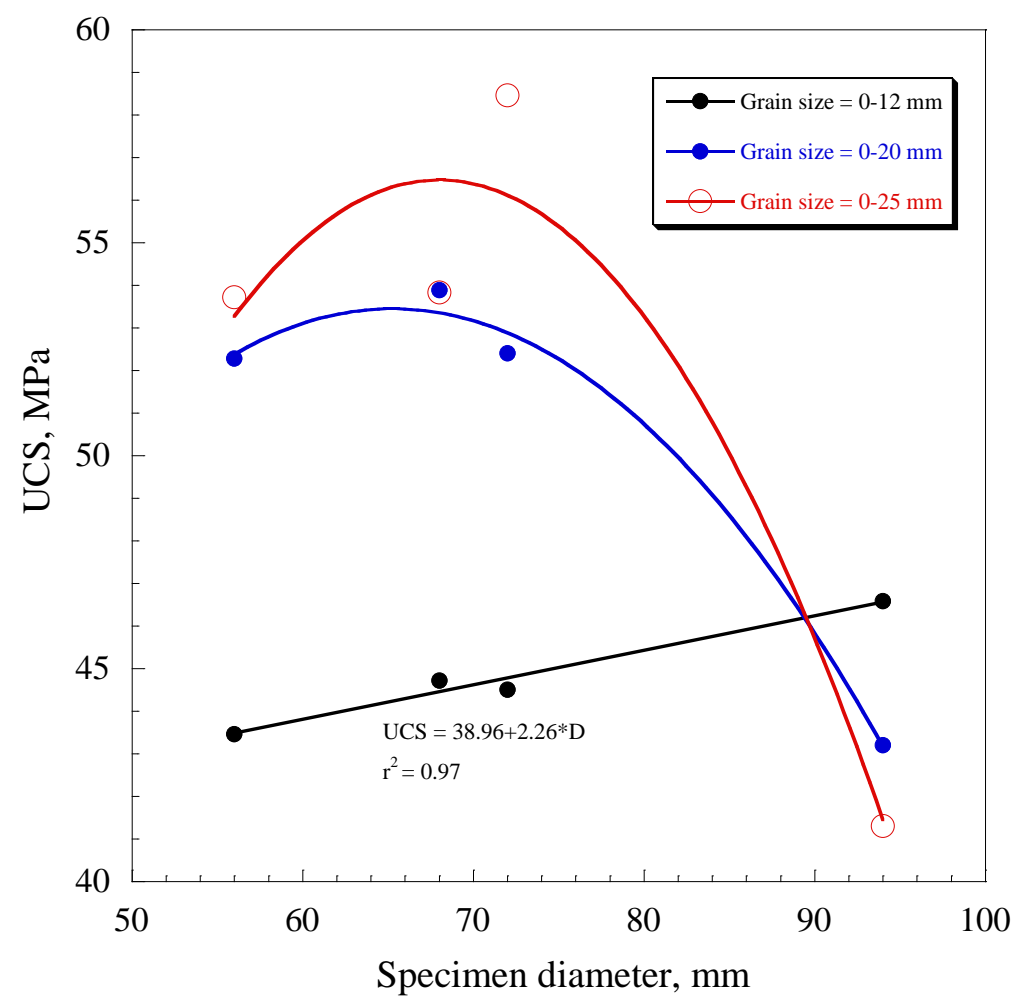

Figure 15. The average UCS of concrete specimens correlated with the diameter of aggregates with the grain sizes of $0-12,0-20$ and $0-25 \mathrm{~mm}$.

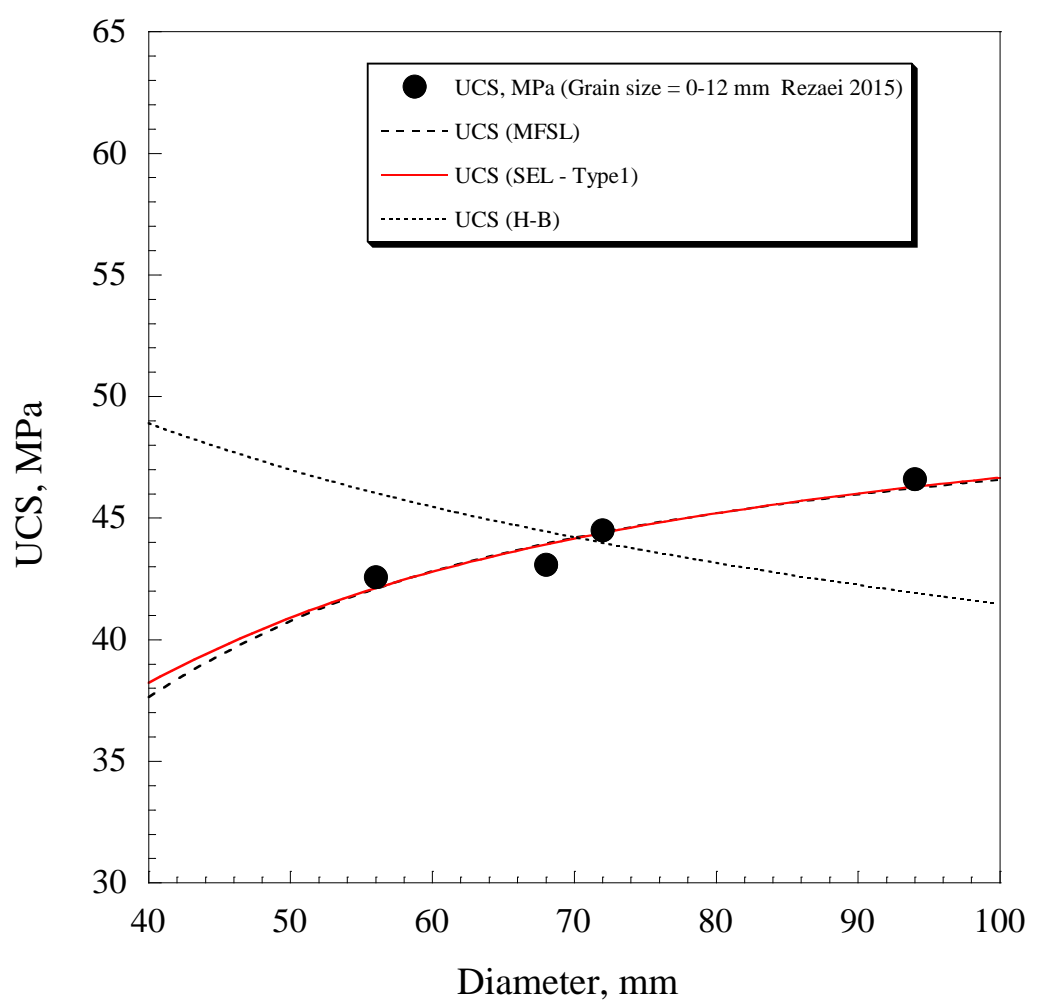

Figure 16. The prediction of uniaxial compressive strength in different diameters for concrete specimens with grain sizes of 0-12 mm using the specimen size effect models of MFSL, SEL-I and HB. 


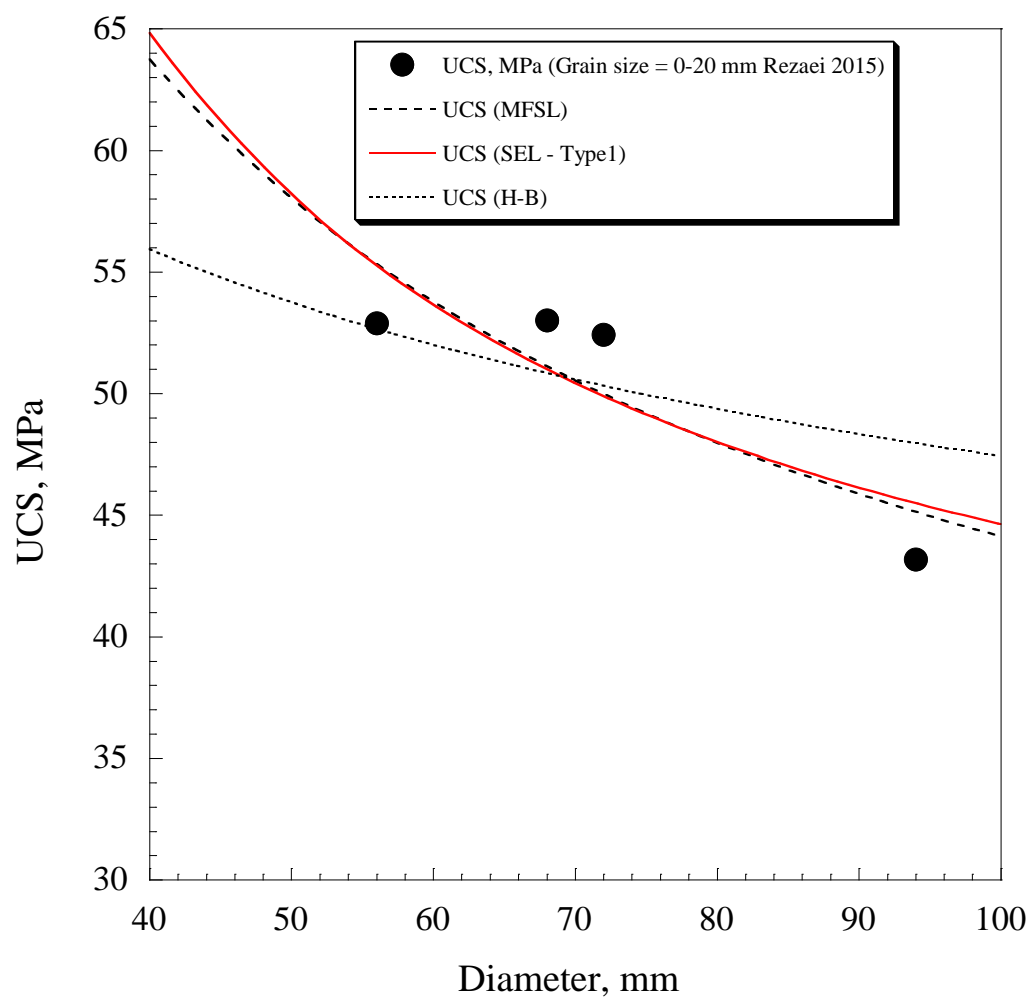

Figure 17. The prediction of uniaxial compressive strength in different diameters for concrete specimens with the grain sizes of 0-20 mm using specimen size effect models of MFSL, SEL-I and HB.

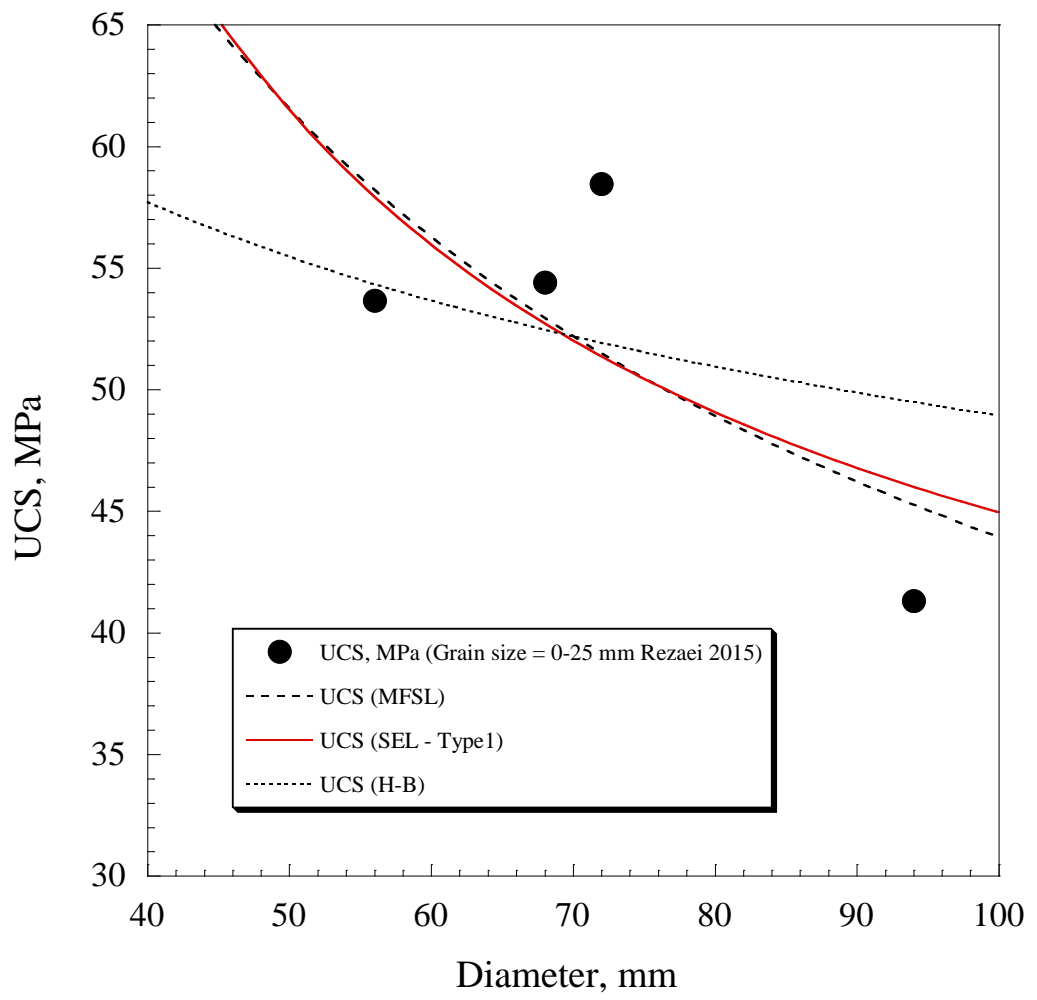

Figure 18. The prediction of uniaxial compressive strength in different diameters for concrete specimens with the grain sizes of 0-25 mm using specimen size effect models of MFSL, SEL-I and HB. 
Table 1. Major studies conducted on the scale effect on the compressive strength of rock and concrete specimens.

\begin{tabular}{|c|c|c|c|c|c|}
\hline $\begin{array}{c}\text { Sample } \\
\text { classification }\end{array}$ & Sample type & $\begin{array}{l}\text { Number of } \\
\text { specimens }\end{array}$ & $\begin{array}{l}\text { Diameter } \\
(\mathbf{m m})\end{array}$ & UCS (MPa) & Reference \\
\hline \multirow{13}{*}{$\begin{array}{l}\text { Sedimentary } \\
\text { rocks }\end{array}$} & Gosford Sandstone & 8 & $19-146$ & $34.6-58.7$ & Masoumi et al. (2014) \\
\hline & Hawkesbury Sandstone & 4 & $18-144$ & $25.3-31.1$ & Pells (2004) \\
\hline & Pilton Sandstone & 8 & $12.5-150$ & $136.8-185.5$ & Hawkins (1998) \\
\hline & Pennant Sandstone & 8 & $12.5-150$ & $45.2-92.2$ & Hawkins (1998) \\
\hline & Hollington Sandstone & 8 & $12.5-150$ & $18.6-34.9$ & Hawkins (1998) \\
\hline & Longmont Sandstone & 4 & $25-100$ & $167.3-171.4$ & Hoskins and Horino (1969) \\
\hline & Bath Stone & 8 & $12.5-150$ & $9.8-19$ & Hawkins (1998) \\
\hline & Burrington Oolite & 8 & $12.5-150$ & $78.4-150.6$ & Hawkins (1998) \\
\hline & Limestone & 6 & $45-79$ & $186.4-206.4$ & Thuro et al. (2001) \\
\hline & Purbeck Limestone & 8 & $12.5-150$ & $48.8-125.1$ & Hawkins (1998) \\
\hline & Clifton Down Limestone & 8 & $12.5-150$ & 61.4- 140.4 & Hawkins (1998) \\
\hline & Yellow Limestone & 33 & $61.5-575.2$ & $2.1-98.5$ & Natau et al. (1983) \\
\hline & Kansas Limestone & 6 & $25-150$ & 48.4- 52.2 & Hoskins and Horino (1969) \\
\hline \multirow{10}{*}{$\begin{array}{l}\text { Hard igneous } \\
\text { rocks }\end{array}$} & Granite & 4 & $51-112$ & $124.5-134.3$ & Thuro et al. (2001) \\
\hline & Lac du Bonnet Granite & 8 & $32.8-294.8$ & 156- 199.2 & Jackson and Lau (1990) \\
\hline & Salida Granite & 3 & $25-76$ & $302.5-337.1$ & Hoskins and Horino (1969) \\
\hline & Inada Granite & 5 & $13-70$ & $140.1-179.9$ & Nishimatsu et al. (1969) \\
\hline & $\begin{array}{l}\text { Ohya Stone (welded tuff) } \\
\text { (loaded horizontally) }\end{array}$ & 4 & $30.2-150$ & $8.1-9.7$ & Yuki et al. (1995) \\
\hline & $\begin{array}{l}\text { Ohya Stone (welded tuff) } \\
\text { (loaded vertically) }\end{array}$ & 4 & $30.2-150$ & 8.3- 9.4 & Yuki et al. (1995) \\
\hline & Ogino Tuff & 7 & $17-70$ & $55.2-67.9$ & Nishimatsu et al. (1969) \\
\hline & Aoishi Sandy Tuff & 5 & $13-70$ & $37.4-42.4$ & Nishimatsu et al. (1969) \\
\hline & Shinkomatsu Andesite & 5 & $13-70$ & 204.9- 249.7 & Nishimatsu et al. (1969) \\
\hline & Saajome Andesite & 5 & $24-70$ & 91.4- 107.3 & Nishimatsu et al. (1969) \\
\hline $\begin{array}{l}\text { Metamorphic } \\
\text { rocks }\end{array}$ & Carthage Marble & 5 & $25-127$ & $101.2-108.2$ & Hoskins and Horino (1969) \\
\hline \multirow{5}{*}{$\begin{array}{l}\text { Artificial } \\
\text { samples }\end{array}$} & Concrete Mortar & 29 & $63.5-300$ & $59.8-75.2$ & Darlington et al. (2011) \\
\hline & Plaster of Paris & 6 & $25.3-152.3$ & 3.6- 3.9 & Hoskins and Horino (1969) \\
\hline & Concrete $(\mathrm{w} / \mathrm{c}=0.53)$ & 7 & 76.2- 914.4 & $22.9-27.9$ & Blanks and McNamara (1935) \\
\hline & Concrete $(\mathrm{w} / \mathrm{c}=0.54)$ & 6 & $50.8-457.2$ & 23-29 & Blanks and McNamara (1935) \\
\hline & Concrete $(\mathrm{w} / \mathrm{c}=0.55)$ & 7 & $50.8-609.6$ & $22.1-28$ & Blanks and McNamara (1935) \\
\hline
\end{tabular}

In all specimens, the length-to-diameter ratio is $2.0(\mathrm{~L} / \mathrm{D}=2.0)$. 
Table 2. The determination coefficient values $\left(\mathrm{R}^{2}\right)$ and parameters of MFSL, SEL-I and Hoek-

Brown models for different types of hard igneous rocks obtained by regression analysis.

\begin{tabular}{|c|c|c|c|c|c|c|c|c|c|}
\hline \multirow{2}{*}{ Reference } & \multirow{2}{*}{ Material tested } & \multicolumn{3}{|c|}{ MFSL } & \multicolumn{4}{|c|}{ SEL-I } & \multirow{2}{*}{$\begin{array}{c}\mathbf{H}-\mathrm{B} \\
\mathrm{R}^{2}\end{array}$} \\
\hline & & $\mathrm{R}^{2}$ & $\mathrm{f}_{\mathrm{c}}$ & $\mathrm{l}_{\mathrm{ch}}$ & $\mathrm{R}^{2}$ & $\mathrm{r}$ & $\mathrm{f}_{\mathrm{r}}^{\infty}$ & $\mathrm{D}_{\mathrm{b}}$ & \\
\hline $\begin{array}{c}\text { Thuro et al. } \\
\text { (2001) }\end{array}$ & Granite & 0.23 & 125 & 4.85 & 0.23 & 1 & 125.12 & 2.29 & 0.11 \\
\hline $\begin{array}{l}\text { Hoskins and } \\
\text { Horino (1969) }\end{array}$ & Salida granite & 0.77 & 293.70 & 8.40 & 0.79 & 1 & 295.25 & 3.73 & 0.82 \\
\hline $\begin{array}{c}\text { Jackson and Lau } \\
\text { (1990) }\end{array}$ & Lac du Bonnet granite & 0.37 & 164.96 & 13.66 & 0.39 & 1 & 165.81 & 6.03 & 0.21 \\
\hline $\begin{array}{l}\text { Nishimatsu et al. } \\
\qquad(1969)\end{array}$ & Saajome andesite & 0.64 & 85.82 & 15 & 0.67 & 1 & 87.05 & 5.56 & 0.53 \\
\hline $\begin{array}{l}\text { Nishimatsu et al. } \\
\qquad(1969)\end{array}$ & Ogino tuff & 0.16 & 61.93 & 2.75 & 0.17 & 1 & 62.16 & 1.23 & 0.06 \\
\hline $\begin{array}{c}\text { Nishimatsu et al. } \\
(1969)\end{array}$ & Inada granite & 0.47 & 149.81 & 6.42 & 0.49 & 1 & 152 & 2.61 & 0.27 \\
\hline
\end{tabular}

MFSL: The multifractal scaling model, Carpinteri et al. (1995); SEL-I: Type I the specimen size-effect model using fracture energy theory, Bazant (1983, 1984); H-B: Hoek and Brown model, Hoek and Brown (1980).

Table 3. The determination coefficient values $\left(\mathrm{R}^{2}\right)$ and parameters of MFSL, FFSEL and HoekBrown models for different types of artificial samples obtained through regression analysis

\begin{tabular}{|c|c|c|c|c|c|c|c|c|c|}
\hline \multirow{2}{*}{ Reference } & \multirow{2}{*}{ Material tested } & \multicolumn{3}{|c|}{ MFSL } & \multicolumn{4}{|c|}{ FFSEL } & \multirow{2}{*}{$\begin{array}{c}\mathbf{H}-\mathbf{B} \\
\mathrm{R}^{2}\end{array}$} \\
\hline & & $\mathrm{R}^{2}$ & $\mathrm{f}_{\mathrm{c}}$ & $\mathrm{l}_{\mathrm{ch}}$ & $\mathrm{R}^{2}$ & $\mathrm{D}_{0}$ & $\sigma_{0}$ & $\mathrm{~d}_{\mathrm{f}}$ & \\
\hline $\begin{array}{c}\text { Blanks and } \\
\text { McNamara } \\
\text { (1935) }\end{array}$ & Concrete $(\mathrm{w} / \mathrm{c})=0.53$ & 0.31 & 23.60 & 21.01 & 0.55 & 2217.26 & 26.61 & 1 & 0.5 \\
\hline $\begin{array}{c}\text { Blanks and } \\
\text { McNamara } \\
\text { (1935) }\end{array}$ & Concrete $(\mathrm{w} / \mathrm{c})=0.54$ & 0.96 & 22.70 & 32.22 & 0.8 & 709.12 & 29.92 & 0.98 & 0.93 \\
\hline $\begin{array}{c}\text { Blanks and } \\
\text { McNamara } \\
(1935)\end{array}$ & Concrete $(\mathrm{w} / \mathrm{c})=0.55$ & 0.89 & 22.29 & 34.50 & 0.87 & 799.2 & 29.24 & 0.99 & 0.95 \\
\hline $\begin{array}{l}\text { Hoskins and } \\
\text { Horino (1969) }\end{array}$ & Plaster of Paris & 0.95 & 3.58 & 10.73 & 0.94 & 706.28 & 4.08 & 1 & 0.97 \\
\hline
\end{tabular}

MFSL: The multifractal scaling model, Carpinteri et al. (1995); FFSEL: The fractal fracture size-effect model, Bazant (1997); H-B: Hoek and Brown model, Hoek and Brown (1980). 
Table 4. The mix design used for manufacturing concrete specimens.

\begin{tabular}{cccccc}
\hline $\begin{array}{c}\text { Block } \\
\text { Number }\end{array}$ & Gravel $\left(\frac{\boldsymbol{k g}}{\mathbf{m}^{3}}\right)$ & Sand $\left(\frac{\boldsymbol{k g}}{\mathbf{m}^{3}}\right)$ & Cement $\left(\frac{\boldsymbol{k g}}{\mathbf{m}^{3}}\right)$ & $\begin{array}{c}\text { Super Lubricant } \\
\left(\frac{\boldsymbol{k g}}{\mathbf{m}^{3}}\right)\end{array}$ & Water $\left(\frac{\boldsymbol{k g}}{\mathbf{m}^{3}}\right)$ \\
\hline 1 & 850 & 830 & 450 & 5 & 175 \\
2 & 950 & 770 & 450 & 5 & 175 \\
3 & 1050 & 705 & 450 & 5 & 175 \\
\hline
\end{tabular}

Table 5. The determination coefficient values $\left(\mathrm{R}^{2}\right)$ and parameters of MFSL, SEL-I and HoekBrown models obtained by regression analysis in the experimental studies conducted on the concrete specimens.

\begin{tabular}{|c|c|c|c|c|c|c|c|c|}
\hline \multirow{2}{*}{ Material tested } & \multicolumn{3}{|c|}{ MFSL } & \multicolumn{4}{|c|}{ SEL-I } & \multirow{2}{*}{$\begin{array}{l}\text { H-B } \\
\mathrm{R}^{2} \\
\end{array}$} \\
\hline & $\mathrm{R}^{2}$ & $\mathrm{f}_{c}$ & $l_{\mathrm{ch}}$ & $\mathrm{R}^{2}$ & $\mathrm{r}$ & $\mathrm{f}_{r}^{\infty}$ & $D_{b}$ & \\
\hline $\begin{array}{c}\text { Concrete } \\
\text { (Grain size }=0-12 \mathrm{~mm})\end{array}$ & 0.89 & 51.68 & 18.79 & 0.9 & 0.5 & 52.77 & 11.91 & 0.92 \\
\hline $\begin{array}{c}\text { Concrete } \\
\text { (Grain size }=0-20 \mathrm{~mm})\end{array}$ & 0.72 & 23.12 & 264.12 & 0.69 & 1 & 31.14 & 43.26 & 0.54 \\
\hline $\begin{array}{c}\text { Concrete } \\
\text { (Grain size }=0-25 \mathrm{~mm})\end{array}$ & 0.47 & 9.04 & 2260.94 & 0.43 & 1 & 28.5 & 57.66 & 0.31 \\
\hline
\end{tabular}

MFSL: The multifractal scaling model, Carpinteri et al. (1995); SEL-I: Type I the specimen size-effect model using fracture energy theory; H-B: Hoek and Brown model, Hoek and Brown (1980). 